\title{
Methylprednisolone Pulse Therapy in COVID-19 as the First Choice for Public Health: When Right Timing Breaks Controversies-Emergency Guide
}

\author{
Luiz Gonzaga Francisco de Assis Barros D'Elia Zanella, ${ }^{1,2 *}$ \\ Daniela Kallíope de Sá Paraskevopoulos ${ }^{1}$, Luciana de Lima Galvãoํㅜ, \\ Augusto Yamaguti ${ }^{1}$
}

\begin{abstract}
${ }^{1}$ Infectious Disease Department-Hospital do Servidor Público do Estado de São Paulo—HSPE (MI-HSPE), Pedro de Toledo Avenue, Vila Clementino, São Paulo, Brazil

${ }^{2}$ School of Medicine-University of São Paulo—PhD Program in Allergy and Immunopathology, Dr. Arnaldo Avenue, São Paulo, Brazil

Email: *luiz.zanella@hc.fm.usp.br
\end{abstract}

How to cite this paper: de Assis Barros D’Elia Zanella, L.G.F., de Sá Paraskevopoulos, D.K., de Lima Galvão, L. and Yamaguti, A. (2021) Methylprednisolone Pulse Therapy in COVID-19 as the First Choice for Public Health: When Right Timing Breaks Controversies-Emergency Guide. Open Journal of Emergency Medicine, 9, 84-114.

https://doi.org/10.4236/ojem.2021.93010

Received: March 4, 2021

Accepted: August 17, 2021

Published: August 20, 2021

Copyright $\odot 2021$ by author(s) and Scientific Research Publishing Inc. This work is licensed under the Creative Commons Attribution International License (CC BY 4.0).

http://creativecommons.org/licenses/by/4.0/

\section{(c) (i) Open Access}

\begin{abstract}
Based on Russian and the Middle East corticosteroids trials in MERS-CoV, we performed methylprednisolone pulse therapy (MPT), resulting in a clinical trial still without result. Our previous cohort (not compared $n=18$ ) showed $76 \%$ of MPT patients did not progress to orotracheal intubation as MTP blocked the cytokine storm, a lower result compared to Tehran's study explained by performing MPT in any lung phase. The Middle East study had been carried out during the initial lung phase. We are in an international emergency. Considering previous protocols and clinical practice, we understand that MPT must be used in COVID-19, and the indication to avoid going to the hospital when the first symptoms appear should be changed urgently for the population with inflammatory comorbidities. This article aims to: 1) show the Iranian protocol to reduce deaths and intubations by COVID-19; 2) present a possible approach to the patient COVID-19 with methylprednisolone pulse and strict criteria for orotracheal intubation to avoid hypoxemia; 3) highlight that there is already a protocol that can be an international guideline-based on the Iranian work for the treatment of COVID-19; and 4) argue that corticosteroids are not controversial, but their use in a period outside the best timing period makes it controversial; and 5) emphasise the urgency of modifying the current protocol that postpones the visit of patients to the hospital in case of symptoms, since late hospital evaluation has been catastrophic for a world population.
\end{abstract}




\section{Keywords}

Methylprednisolone, COVID-19, Pulse-Therapy, Hypoxemia

\section{Introduction}

Methylprednisolone [1] [2] [3] [4] [5] is a well-known and low-cost drug with broad access to the population, with which we have a good practice of its use for treating already known diseases. Supported by studies in the Middle East [2], which provides the pulse's effectiveness using $250 \mathrm{mg}$ of Methylprednisolone and our choice relies on pulsing with a large and classic dose-1000 $\mathrm{mg}$ on the first day to $500 \mathrm{~g}$ on the second and third days. These higher doses attempt to block neutrophils from bone marrow riding into the tissues infected with Sars$\mathrm{CoV}-2$, mainly to the lungs.

Avoiding the migration of neutrophils is to avoid three catastrophes: 1) cytokine storm that leads the patient to respiratory failure and, consequently, orotracheal intubation; 2) development of autoantibodies by NETose and by activation of the complement system secondary to the formation of immune complexes; 3 ) immunoparalysis, a phase in which phagocytes lose the ability of phagocytosis to secrete IL-6 intensely; in an environment tending to tolerance [6] [7] [8].

Performing pulse therapy with Methylprednisolone requires that the patient be very well evaluated, as he needs to be at least on the sixth day of the onset of symptoms due to viral load curve. This delta T (D6 and cytokine storm) is short, so you must evaluate some parameters that will indicate the best period.

We have been facing the COVID-19 era for almost one year, and little information about the management of COVID-19 patients profoundly changed the prognostic regarding severe cases. The controversial use of corticosteroids can be broken when the timing is considering its use. This article is a little review of clinical practice toward corticosteroid use in COVID-19.

\section{Methods}

\section{Inclusion Criteria for Articles}

Articles related to high doses of corticosteroids we used: "Methylprednisolone" And "COVID-19" AND "PULSE". We used articles published between January 2019 and May 2021, in English or with publication translated into English. Russia and the Middle East option was because we found many articles and trials developed with Methylprednisolone (MTP) protocols that we hardly find in the West. Other countries were placed because they have some trials with high doses of corticosteroids, but they also do not come close to classic pulse doses such as $1 \mathrm{~g}$ or $500 \mathrm{mg}$ of MTP. Therefore, we discard articles with low doses of corticosteroids or not standardised doses-pulse therapy arbitrarily defined as treatment with more than $250 \mathrm{mg}$ prednisone or its equivalent per day, for one or 
more days. Other possible definition is $250 \mathrm{mg}$ per day, or 10 to $20 \mathrm{mg}$ per kilogram of body weight for methylprednisolone $(250-1000 \mathrm{mg})$ and 2 to $5 \mathrm{mg}$ per kilogram of body weight (50 - $200 \mathrm{mg}$ ) for dexamethasone. Single doses of 500 $\mathrm{mg}$ of methylprednisolone and $100 \mathrm{mg}$ of dexamethasone are both considered equivalent to $625 \mathrm{mg}$ of prednisone. The articles considered needed to address only COVID-19, so those that addressed COVID-19 plus another disease were discarded. Any type of study was considered to this article analysing GOOGLE scholar and PubMed platforms (Figure 1). Other articles were used to review the specific issues covered in this article. All articles were found on the PubMed platform. Evaluated according to publication quality, considering fidelity to the precepts of science, even if the publication was in a journal with a lower rate of evaluation. Arbitrarily, the first 100 articles on the topic were considered. Only those articles that used "classic pulse therapy" or high doses of corticosteroids, that is, $500 \mathrm{mg}$ to $1 \mathrm{~g}$ of Methylprednisolone or doses of another equivalent corticosteroid, or a dose considered pulse within the definitions of this article, or articles that showed controversies about corticosteroids use were separated. A total of 63 articles were eligible, and only 29 of them were under the criteria. The table (Table 1) was constructed using 7 articles, among those found, that could exemplify controversies and good use of corticosteroids at the authors' choice. All of them cited in the references [1] [2] [3] [4] [5] [9]-[30].

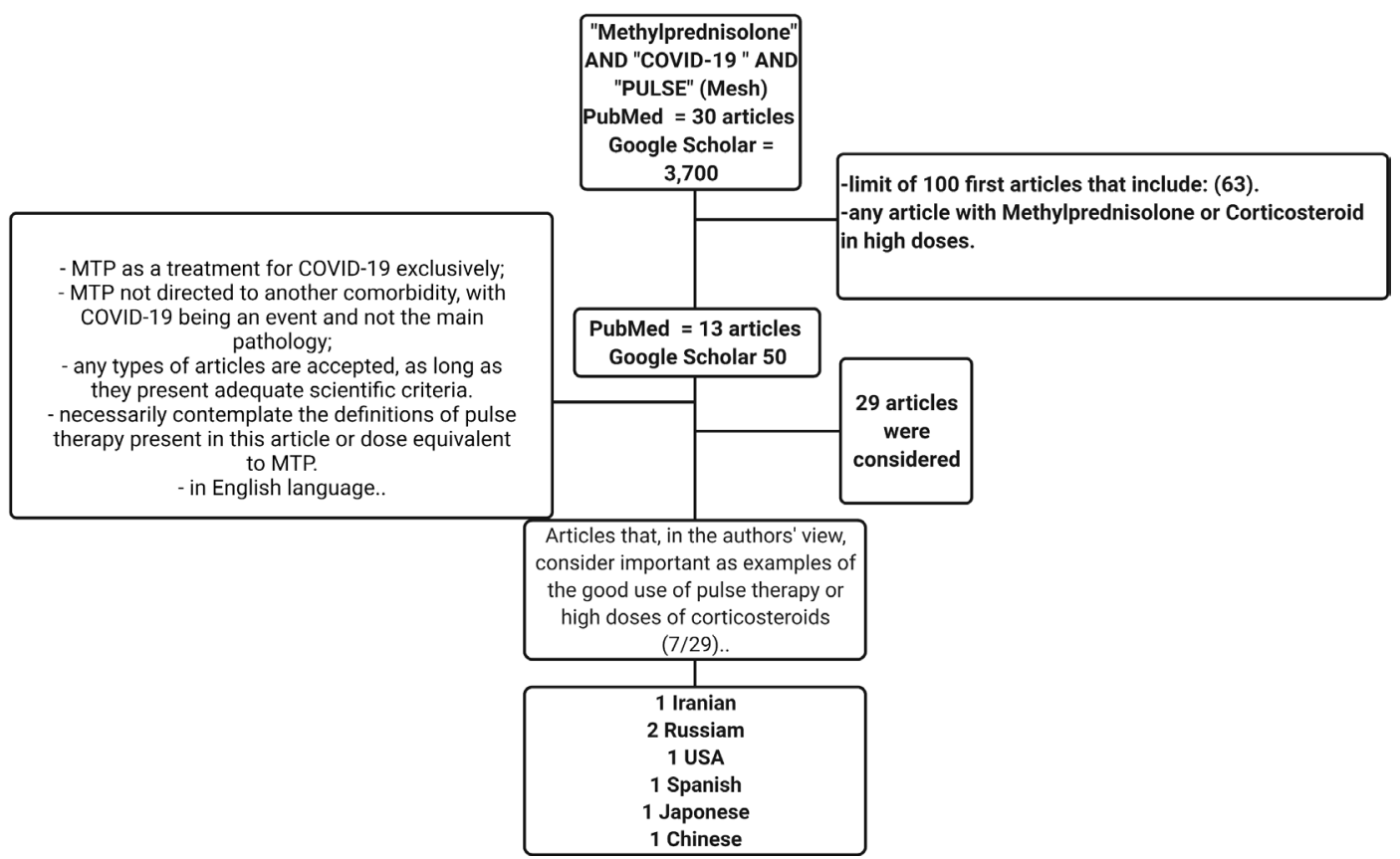

Created with https://biorender.com/

Figure 1. The rationale for selecting articles from Table 1. This flowchart explains Table 1, "from controversies to proper use of corticosteroids in COVID-19 patients". Table 1 shows some articles that exemplify the controversial issues about the use of corticosteroids in COVID-19 to the use of Corticosteroids in the form of pulse therapy. The choice of 7 articles for the table was based only on personal criteria with the initiative of presenting at least 1 article evidencing controversies and others evidencing the use in high doses of the drug and therapeutic success. 
Table 1. From controversies to proper use of corticosteroids in COVID-19 patients.

\begin{tabular}{|c|c|c|c|c|c|c|}
\hline Title & Origin & Methodology & Participants & Indication & Dose & Outcome \\
\hline $\begin{array}{l}\text { Intravenous MP pulse } \\
\text { as treatment for } \\
\text { hospitalized covid-19 } \\
\text { critical patients: results } \\
\text { of a randomized } \\
\text { controlled trial4 }\end{array}$ & Iran & $\begin{array}{l}\text { Randomized } \\
\text { Clinical Trial }\end{array}$ & $\begin{array}{l}68 \text { TOTAL } \\
\text { 34: MP intervention, } \\
\text { 28: Standard, } \\
\text { 06: deleted }\end{array}$ & $\begin{array}{l}\text { Early pulmonary phase } \\
\text { (Non-IOT Patients) }\end{array}$ & $\begin{array}{l}\text { Methylprednisolone } \\
250 \mathrm{mg} \text { (03 days) }\end{array}$ & $\begin{array}{l}\text { Mortality rate was lower in } \\
\text { the Methylprednisolone } \\
\text { group ( } 5.9 \% \text { versus } 42.9 \% \text {; } \\
\text { p }<0.001)\end{array}$ \\
\hline $\begin{array}{l}\text { Efficacy of MP pulse } \\
\text { therapy in patients with } \\
\text { COVID-192 }\end{array}$ & Russia & $\begin{array}{l}\text { Retrospective } \\
\text { Analysis }\end{array}$ & 57 & ??? & $\begin{array}{l}\text { Methylprednisolone } \\
500 \text { mg (03 days) }\end{array}$ & $\begin{array}{l}\text { Decrease in inflammatory } \\
\text { tests. No patients transferred } \\
\text { to the ICU. }\end{array}$ \\
\hline $\begin{array}{l}\text { Impact of } \\
\text { Corticosteroids on } \\
\text { Coronavirus Disease } \\
\text { Results } 201918\end{array}$ & USA & $\begin{array}{l}\text { Systematic } \\
\text { Review }\end{array}$ & $\begin{array}{l}\text { Review of } 73 \text { studies } \\
\text { (21,350 patients). } \\
\text { Database (PubMed, } \\
\text { MEDLINE and } \\
\text { EMBASE) of the } \\
\text { literature published } \\
\text { until July 22, 2020, }\end{array}$ & $\begin{array}{l}\text { Critically ill patients } \\
\text { under mechanical } \\
\text { ventilation or in an } \\
\text { ICU environment. }\end{array}$ & Varied & $\begin{array}{l}\text { Corticosteroids showed } \\
\text { benefit in critically ill } \\
\text { patients.(OR, 0.65; 95\% CI, } \\
0.51 \text { - 0.83; } \mathrm{p}=0.0006) \text {. } \\
\text { However, it was not possible } \\
\text { to identify a greater benefit } \\
\text { according to high or low dose } \\
\text { regimens. The analysis was } \\
\text { limited by highly } \\
\text { heterogeneous literature for } \\
\text { high-dose and low-dose } \\
\text { corticosteroid regimens. }\end{array}$ \\
\hline $\begin{array}{l}\text { MP pulses in the second } \\
\text { week improve prognosis } \\
\text { in patients with severe } \\
\text { coronavirus disease } \\
2019 \text { pneumonia: } \\
\text { An observational } \\
\text { comparative study using } \\
\text { routine care data.19 }\end{array}$ & Spain & $\begin{array}{l}\text { Comparative } \\
\text { observational } \\
\text { study }\end{array}$ & $\begin{array}{l}242 \text { patients with } \\
\text { COVID-19 and } \\
\text { elevation of } \\
\text { inflammatory } \\
\text { markers }\end{array}$ & From the 8th day & $125-250 \mathrm{mg} / \mathrm{d} \times 3$ & $\begin{array}{l}\text { The HR adjusted for death } \\
\text { and death or IOT for patients } \\
\text { in the MP group was } 0.35 \\
\text { ( } 95 \% \text { CI } 0.11 \text { to } 1.06, \mathrm{p}= \\
0.064 \text { ) and } 0.33 \text { ( } 95 \% \text { CI } 0.13 \\
\text { to } 0.84, \mathrm{p}=0.020 \text { ), } \\
\text { respectively. This difference } \\
\text { was specifically seen in the } \\
\text { subcohort of patients with } \\
\text { spo } 2 / \text { fio } 2 \text { ratio lower than } \\
353 \text { on the } 7 \text { day of disease. }\end{array}$ \\
\hline $\begin{array}{l}\text { High dose, short-term } \\
\text { corticosteroids for ARDS } \\
\text { caused by COVID-19: a } \\
\text { number of cases. } 12\end{array}$ & Japan & Case series & 07 & $\begin{array}{l}\text { Critically ill patients } \\
\text { under IOT }\end{array}$ & $\begin{array}{l}500-1000 \mathrm{mg} / \mathrm{day} \\
(03 \text { days }) \mathrm{MP} \\
\text { followed by } 1 \mathrm{mg} / \mathrm{kg} \\
\text { in progressive } \\
\text { reduction. }\end{array}$ & $\begin{array}{l}\text { All patients extubated within } \\
07 \text { days. }\end{array}$ \\
\hline $\begin{array}{l}\text { The Effects of Steroids in } \\
\text { Severe Hospitalized } \\
\text { Patients with COVID-19 } \\
\text { A Retrospective Cohort } \\
\text { Study20. }\end{array}$ & China & $\begin{array}{l}\text { retrospective, } \\
\text { two-centred, } \\
\text { cohort study }\end{array}$ & $\begin{array}{l}760 \text { hospitalized. } \\
659 \text { patients were } \\
\text { excluded because In } \\
\text { total, } 101 \text { included: } \\
39 \text { in the steroid } \\
\text { group and } 63 \text { in the } \\
\text { non-steroid group }\end{array}$ & $?$ & $\begin{array}{l}\text { median dose of MP } \\
\text { was } 80 \text { mg daily } \\
\text { ( } 40-160 \mathrm{mg} \text { daily), } \\
\text { and } 38(90.5 \%) \\
\text { received } \\
\text { methylprednisolone } \\
\text { or equivalent < } 150 \\
\text { mg. CTCD was } \\
\text { initiated within } 13 \\
\text { days ( } 9 \text { - } 22 \text { days) }\end{array}$ & $\begin{array}{l}\text { short-term corticosteroids at } \\
\text { low to moderate doses did } \\
\text { not improve the clinical } \\
\text { outcomes for patients with } \\
\text { severe COVID-19. }\end{array}$ \\
\hline
\end{tabular}




\section{Continued}

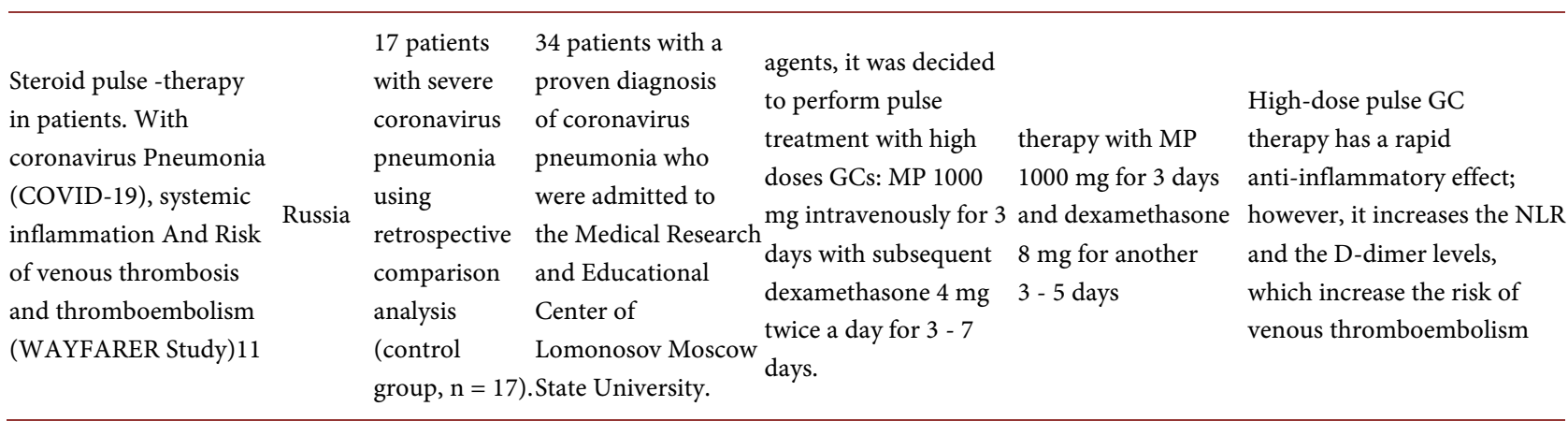

\section{Results}

\subsection{The Best Period for Pulsing and Essential Information}

With a patient still stable and necessarily with $\mathrm{PaO}_{2} / \mathrm{FiO}_{2}>200$ without supplementation. $\mathrm{SatO}_{2}>93 \%$ or arterial blood gases showing $\mathrm{PaO}_{2}>60$ and or oxygen saturation greater than $93 \%$ (Figure 2).

Do not wait C-reactive protein to reach a high serum concentration: C-reactive protein marks the cytokine storm, and its peak is causally related to lymphopenia that usually occurs between days 8 and 10, counted from the onset of symptoms. This phase is preceded by neutrophilia progressively scaled to the left with a significant increase on the peak day of CRP [2] [31] (Figure 3).

\subsection{Avoid Hypoxemia}

Hypoxemia tends the immune response to tolerance with maintained inflammatory status with tumorigenic characteristics as we have described before [32].

Never avoid intubation in time due to pronation. Pronating should never postpone intubation when a tube is well indicated to avoid hypoxemia and depletion of the energetic reserves (Figure 4).

\subsection{Delayed Perception of Inflammation}

Attention to diabetic, obese, and elderly patients: obese and diabetic patients already have macrophage activation for the IL- 6 axis. They take longer to notice inflammation caused by the virus. Thus, when they are admitted reporting, for example, 4 or 5 days of symptoms, they are already presenting a chest image with bilaterally affected lungs like a later stage of the disease (D10-D12). Thus, this population should never wait for the worsen in their homes. At the slightest sign of symptoms, this population should be well evaluated and hospitalised until it is necessary to pulse or even perform orotracheal intubation [33] [34] [35] [36].

\subsection{Immunosuppressed Patients}

Our Protocol excludes immunosuppressed patients: HIV patients with CD4+< 300 , cancer, transplant patients or by the clinical evaluation of the responsible physician. In these cases, the recommendation is not to let the patient evolve to a 
COVER-ME-UP PROTOCOL: Criteria for pulse MTP immediately after the viraemic phase or early pulmonary phase

Patients have a diagnosis of COVID-19 (I) and concomitant evidence of Cytokine Storm Syndrome (II) AND PREFERENTIALLY WITH $\mathrm{PaO}_{2} / \mathrm{FiO}_{2}>200$.

\section{I-COVID-19 Diagnosis:}

A) RT-PCR-SARS-COV-2 positive or

B) Consider the evaluation of the IgM class with the presence or not of IgG, associated with the clinical and tomographic image compatible with COVID-19, and negative RT-PCR-Sars-CoV-2 exam: Keep the note on the CT OR

C) high clinical probability (desaturation below $90 \%$ in arterial blood gases, excluding other causes) in the presence of negative A and $\mathrm{B}$

D) CT image result compatible with CORADS 3, 4 OR 5.

\section{II-Definition of Cytokine Storm Syndrome:}

A) Patient with oxygen saturation (Sat $\mathrm{O} 2$ ) $<94 \%$ at rest (with $\mathrm{O}_{2}$ catheter at maximum $6 \mathrm{~L} / \mathrm{min}$ flow) OR with blood oxygen saturation $<90 \%$ by the oximeter.

OR

B) Mild tachypnoea-respiratory rate $>18 \mathrm{bpm}$ (although the definition used RR $>30$, for inclusion, we need that the patient is in good clinical condition and not deteriorated in case of a respiratory rate greater than or equal to 30 ).

AND

C) Have two altered BIOMARKERS: C-reactive protein greater than 10, ferritin and d-dimer with or without leucocytosis, preferably IL-6 if available.

\section{However, consider PCR $<10$ avoiding the cytokine storm.}

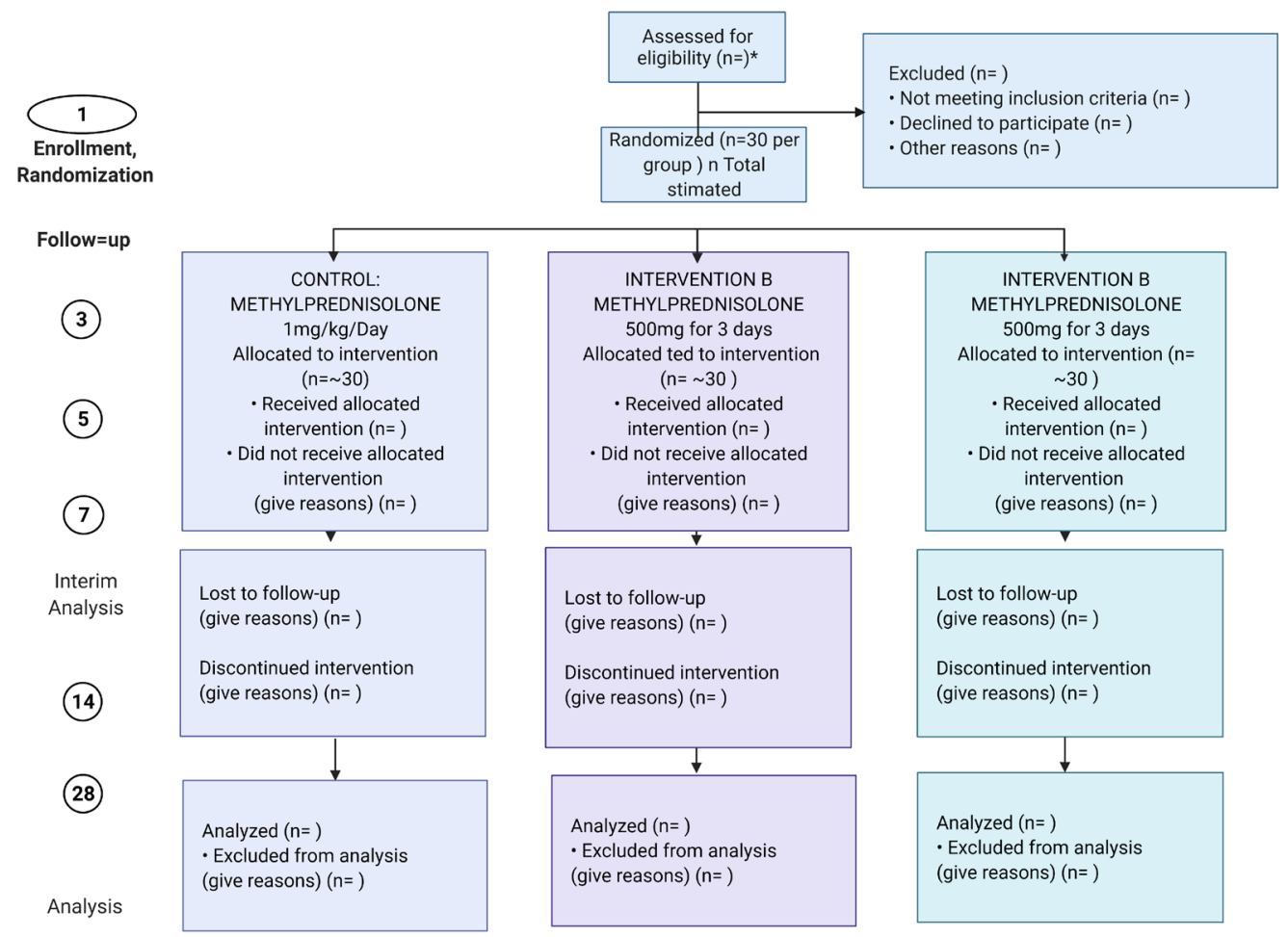

Created with https://biorender.com/

Figure 2. Criteria for pulse therapy with Methylprednisolone from the "COVER-ME-UP" study. According to the most current studies, there is no placebo group, as corticosteroids are the only drug that shows a difference in patient outcomes-Methylprednisolone $250 \mathrm{mg}$ following the Iranian protocol, Methylprednisolone $500 \mathrm{mg}$ following the classic pulse idea. The idea is to compare side effects between the Iranian protocol and the classic pulse and observe if there is any difference in the outcome comparing doses of $250 \mathrm{mg}$ with $500 \mathrm{mg}$ of MTP. $\mathrm{n}=30$ for each group was performed based on our observational cohort concerning the original Iranian study and based on statistical calculation, considering the group sample space with comorbidities, which are predictors of severity. The best period to perform pulse therapy: between D6 - D8 after symptoms have started; Preferably before CRP $<10$, or in ascending CRP.-interleukin (IL)-6 (>6) at the early pulmonary phase of disease before connecting to the ventilator and intubation. We use only CRP at HSPE; $\mathrm{O}_{2}$ saturation $<90 \%$ without supplementary $\mathrm{O}_{2}$; RR $>18$ and little dyspnoea; and preferably before CRP peak, where neither lymphopenia nor neutrophilia has not already happened. 


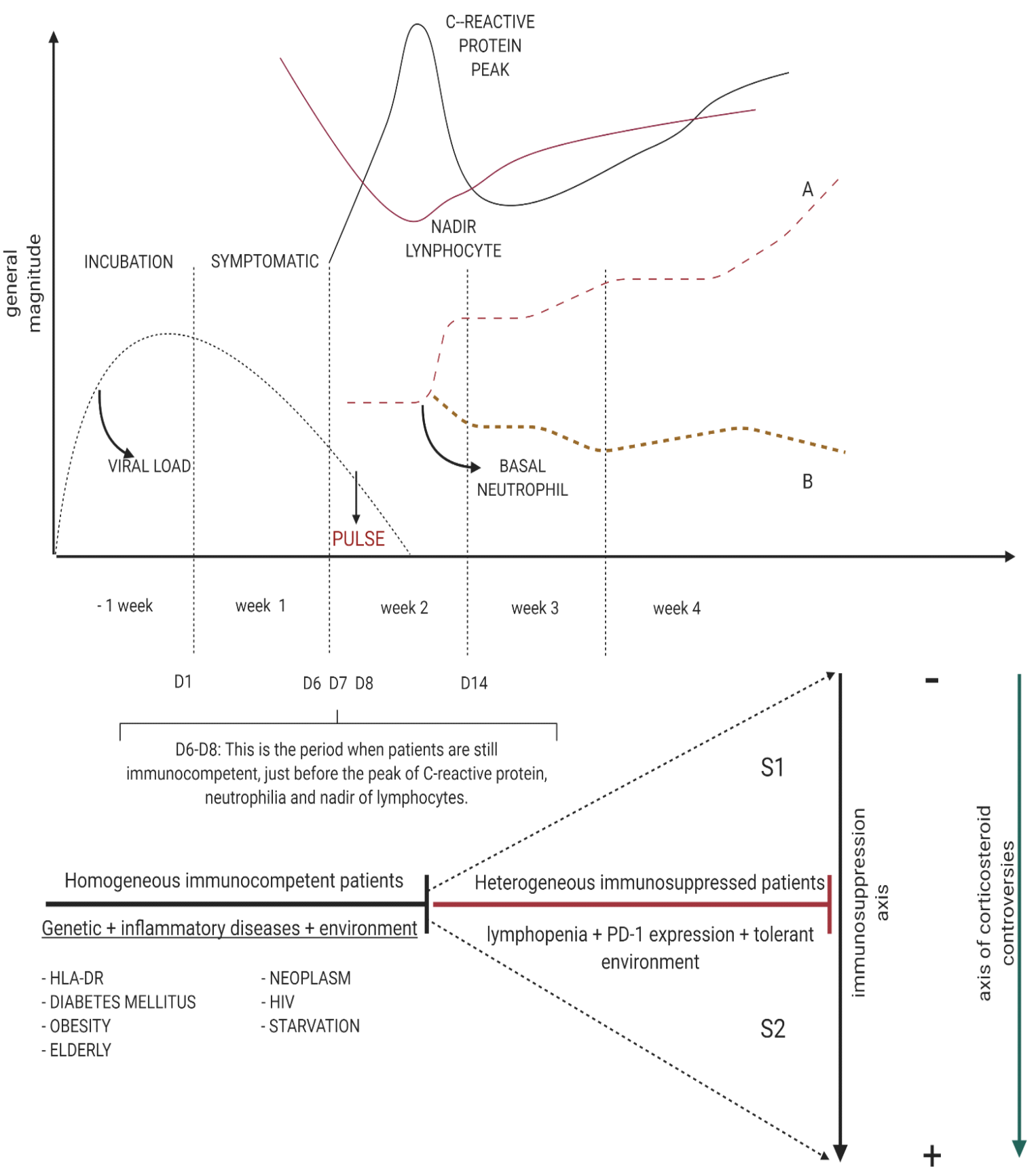

Created with https://biorender.com/

Figure 3. The rationale behind corticosteroid therapy. Upper figure. COVID-19 progression concerning viral kinetics, week of infection. A. the patient who evolves with a leukemoid reaction and neutrophilia is sometimes mistakenly diagnosed as acute leukaemia, but it is common in Sars-CoV-2 infection in patients who evolve severely. B. indicates patients who develop neutropenia and who, in general, are discharged after 14 days of illness. Lower figure. Immunosuppression initiated with the cytokine storm followed by the formation of immunological heterogeneity responsible for the controversy regarding the use of corticosteroids. S1: triangle's area represents patients with lesser and heterogenous immunosuppression; S2: triangle's area allocates patients with more immunosuppression and heterogeneity. Thus, pulse therapy is indicated before the immunosuppressive phase, initiated with the peak of reactive Protein C. The initial phase shows some inflammatory comorbidities, MHC class II genes and chronic infections responsible for the chronic inflammatory profile of patients who progress to severe forms of the disease. It is necessary to emphasize that even lymphocyte recovery is not enough to restore normal immunity, since many articles already show that the recovered lymphocytes, in great majority, are in exhaustion expressing PD-1 protein. 


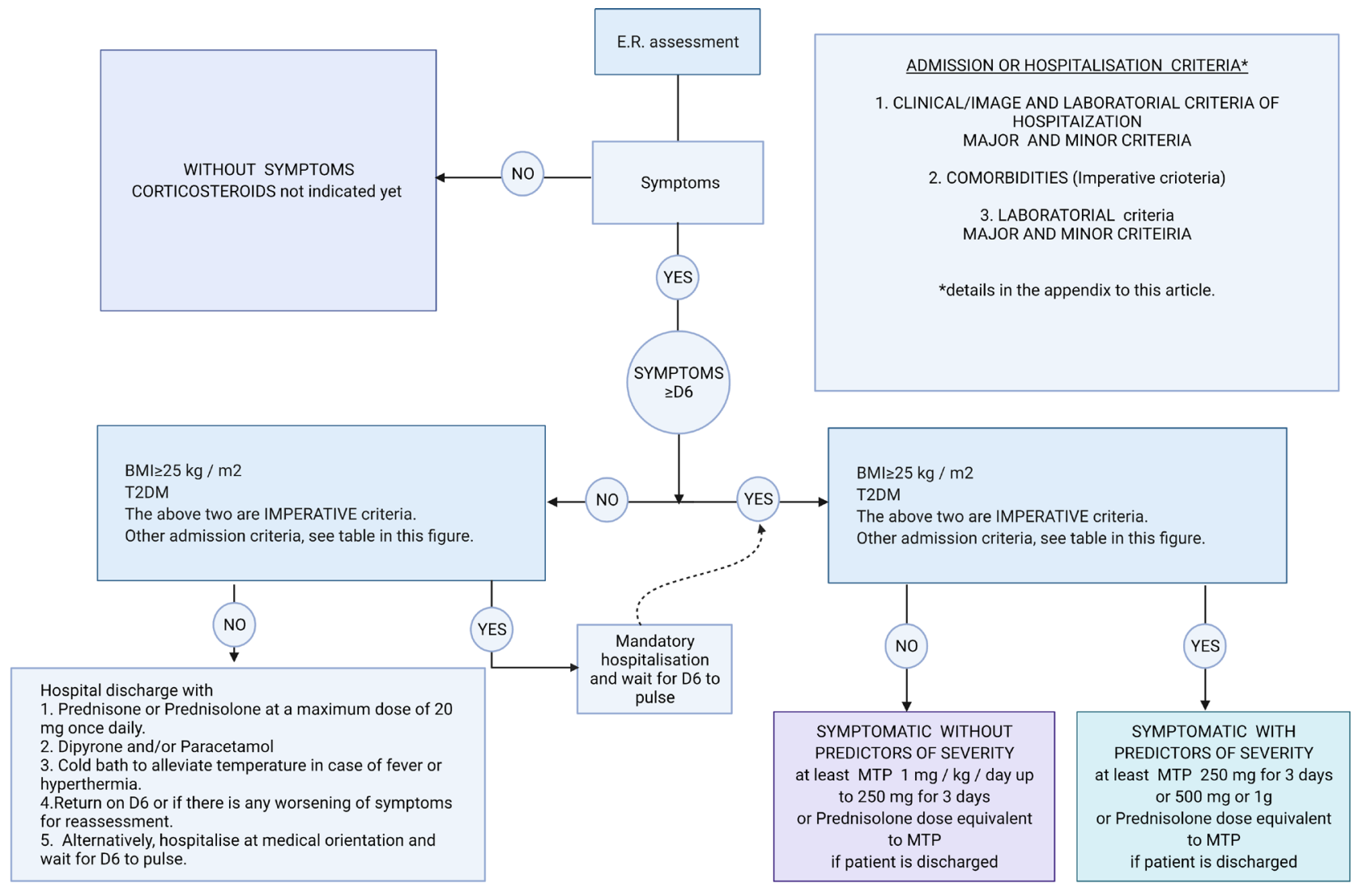

Created with https://biorender.com/

Figure 4. A E.R. guide to Pulse therapy with Methylprednisolone. The restricted criteria based on the author's perception; however, this flowchart follows a general thought: admission screening can follow specific parameters of each hospital as long as the final approach aims at whether the patient has comorbidities predicting severity and considering viral kinetics to be able to perform pulse therapy from the sixth day counted from the onset of symptoms (D6). This flowchart is adaptable to the characteristics of any hospital and its definitions of admission criteria. This figure shows the author's definition of hospitalization criteria.

hypoxemic state, performing intubation in time whenever BR $>30$, SatO2 $\leq 92$. Use standardised corticosteroids and perform pulse therapy if there is a consensus between physicians about pros and cons, considering the immunosuppression by COVID-19.

\subsection{Thromboembolism}

Thromboembolism is common in patients with COVID-19, admittedly in the intensive care unit, despite thromboprophylaxis. In COVID-19, vascular injury is induced by endocytosis of SARS-CoV-2 by host cells, causing them to undergo pyroptosis, in addition to a consecutive cascade of immunological, metabolic and genetic mechanisms that, together, trigger thrombotic phenomena. Much of the pathophysiology has been associated with platelet activation and tissue damage, but nothing is conclusive yet. It is known that perhaps exhaustively and empirically anticoagulated therapeutically can worsen the bleeding outcome. To date, there are few and careful study that uses acetylsalicylic acid (ASA) associated with Heparin in prophylactic doses that may suggest the use of a drug low 
cost and affordable as is the ASA [37]-[43].

\subsection{The Side Effect of Methylprednisolone}

With the 18 patients in an observational study, we could observe an increase in serum glucose values and some hypertensive events, which were drug-induced.

We do not have provisional data in the randomized trial that is being carried out yet, but they will be released soon.

An observation regarding sustained disglycemia: it is important to note that one of the inflammatory pathways in COVID-19 is oxidative stress. This route has been responsible for maintaining disglycemia in patients, as these changes occur even when the patient is no longer using corticosteroids.

\subsection{The Questionable Use of Corticosteroids in COVID-19: A Question of Timing}

To reveal the essence of corticosteroids' controversies, we organised a little review (Table 1) with different results and with no definition of corticosteroids in Sars-CoV-2 infection. It is necessary to consider the heterogeneity of patient's phenotypes (Figure 3) that are spectra of a unique disease, for example, the same disease "diabetes" has a different expression for two different people.

COVID-19 causes important and variable immunosuppression. Sars-CoV-2 causes immunosuppression by forcing the macrophages to IL- 6 polarisation and by apoptosis of lymphocytes. These lymphocytes can be recovered in numbers, but the microenvironment provided by IL- 6 shapes immunity to a state of immunoparalysis. This entity was described in a pre-COVID-19 era and resulted from a state of "catatonia" of the immune system in which the phagocytic response is globally diminished, and the lymphocytes have high expression of PD-1 exhaustion protein. This fact can explain fungal, mycobacterial and pneumocystis coinfection in some autopsies [44] [45] [46].

\section{Discussion}

To perform MPT in the Early Pulmonary Phase. The percentage of improved patients in Tehran was higher in the methylprednisolone group than in the standard care group (32 (94.1\%) versus $16(57.1 \%) ; \mathrm{p}=0.001)$. The mortality rate was significantly lower in the methylprednisolone group (2 (5.9\%) versus 12 (42.9\%); $\mathrm{p}$ < 0.001). MI-HSPE cohort (performed from June-20 to December-20) without control group had 76\% non-intubating patients among all patient that was pulsed ( $\mathrm{n}=16$ without missing data) vs. $94.1 \%$ Tehran trial. This difference happened in our previous non-comparative cohort, we pulsed some patients in the late pulmonary phase because these patients were admitted to the hospital between D8-D12 or more when cytokine storm has already started. A variable period of immunosuppression [47] [48] characterises and mark by different immune profiles and it is the possible answer to corticosteroids controversial use in COVID-19. Variable immunosuppression post cytokine storm is the hidden pathophysiology that explains the idea: cytokine storm IL-6 mediated causes 
lymphopenia due to apoptosis and $\mathrm{T}$ cell migration from de peripheral blood to tissues infected by Sars-CoV-2, since TCD8+ PD-1+, TCD4+ PD1+, and express homing molecules. Phagocytes also express $\mathrm{PD}-1$, and their phagocytic function is blocked [49] [50] [51].

Up to CRP peak, patients' immune system is homogeneous, and after lymphopenia occurred during CRP peak, an emergent $\mathrm{T}$ cell expressing PD-1 (an exhaustion marker expressed by some cells) protein emerge. These $\mathrm{T}$ cells express low levels of cytotoxic molecules and displayed a compromised capacity to produce pro-inflammatory cytokines while the expression of anti-inflammatory IL-10 was up-regulated, and a tendency to apoptosis is real. Nevertheless, they are exhausted, and with diminished function and phagocytes, such phagocytosis is deficient as translocation from skin and gut is familiar with refractory bacteraemia, where many antimicrobial drugs are used [52] [53].

\section{Conclusions}

This informed content is about clinical experience acquired in 11 months taking care and managing COVID-19 patients. We have blocked neutrophil migration based on pulse therapy performed by other studies. However, now, our trial intends to prove, by randomised study, that it happens and can avoid deaths. Up to now no Brazilian trials with classical corticosteroids pulse have already been performed. We advise that the articles indicated in this report are examples that other centres also have the initiative to act on the disease's progression by pulse therapy, especially thinking about the possibility of more evidence.

It is important to note that it is necessary to modify the care protocol, so patients with inflammatory comorbidities, especially obesity, diabetes and aging need to be seen and admitted to hospitals as early as possible-between D4 and D6-so that they can receive the pulse. Methylprednisolone at the best time. This strategy looks like it will overcrowd hospitals. Initially, emergency rooms may have too many people allocated. However, this measure will avoid overcrowding in ICUs, since we brought these patients to hospitals and performed an intervention that blocks the progression to orotracheal intubation, so there will be more free spaces in ICUs, the length of stay falls significantly, as does the cost of the length of stay for each patient.

There is a fear of overcrowding in hospitals, but changes are needed since the methods have been applied for one year, not blocked COVID-19 severity and death. However, when performing an MPT at an appropriate time, the length of hospital stay drops to 7 to 10 days, while the late arrival of the diabetic and obese patient to hospitals has hospitalization messages long periods with the complicated post-ICU period. Although our study is ongoing, we observed a good result when we chose to perform the Teheran protocol in some critically ill patients with comorbidities that predict severity. This article passes for being a report of international importance, showing that the hospitals must carry out clinical studies with MTP in the precocious pulmonary phase and before the immunosuppression of COVID-19. 
It is important to consider that Methylprednisolone is not the unique treatment for COVID-19. Maybe each drug has a specific timing. Antivirals, for example, must be administered in the initial phase of the disease. From D6 of the onset of symptoms, there is hardly any virus causing the disease. From D6 onwards, a period of defervescence begins, usually, 1 to 3 days, followed by a toxaemic/inflammatory phase, like Yellow Fever (when they progress to severe haemorrhagic fever) or Leptospirosis (Weil's Syndrome). Corticosteroids may also play an essential role in the later stages of the disease. Perhaps, in the future, the association of anti-inflammatory drugs will allow corticosteroids in lower doses and for the shortest time possible. For those who seek the hospital service between D6 and D8 of the onset of symptoms, corticosteroids might be the best treatment. In the later stages, because they are inflammatory, perhaps corticosteroids also play an essential role, but perhaps the association of anti-inflammatory drugs is the solution to using lower doses of corticosteroids and for as little time as possible.

The simplified following Protocol is based on Tehran's Protocol modified by COVER-ME-UP protocol for emergency times (more about COVERME-UP criteria on Appendix).

I) Emergency to modify the information about when to seek hospital help:

1) Obese, elderly $>60$ years old and diabetics need to be at the hospital for clinical evaluation, as soon as the first symptoms are noticed.

2) Healthy young people can wait for 5 to 6 days for symptoms to start in case of worsening, but the use of corticosteroids should be indicated after D6.

Rationale: the best time to block COVID-19 progression is on D6-D8 (before the cytokine storm and the neutrophil marching), but with the current indication for hospital help, patients are admitted late, and COVID-19 block is not it is just as effective when pulse therapy is performed previously.

II) Clinical and laboratory criteria for admission in select urgency/emergency areas to symptomatic patients

1) Obese, diabetic, elderly $>60 \mathrm{y} / \mathrm{o}$. They need to be early admitted to the hospital and have the assessment started at the beginning of the symptomatic phase showed in week 1 (Figure 1).

2) Exams: arterial blood gas (ABG) analysis WITHOUT supplementary $\mathrm{O}_{2}$, hemogram with platelets, sodium, calcium ionic, potassium, magnesium, urea, creatinine, LDH, troponin, D-dimer, ferritin, urine exam, AST/ALT, electrocardiogram.

III) Pulse-therapy criteria: One of the "the best period" criterium below is present?

If YES-perform pulse; if NO-wait for the best period.

The best period to perform pulse therapy.

- Between D6 - D8 after symptoms have started.

- Preferably before CRP $<10$, or in ascending CRP.-interleukin (IL)-6 (>6) at the early pulmonary phase of disease before connecting to the ventilator and intubation. We use only CRP at HSPE. 
- $\mathrm{O}_{2}$ saturation $<90 \%$ without supplementary $\mathrm{O}_{2}$ (See in the appendix first author consideration).

- $\quad$ RR $>18$ and little dyspnoea.

AND

Preferably before CRP peak, where neither lymphopenia nor neutrophilia has not already happened (Figure 3).

IV) Orotracheal Intubation criteria (OTI)

Central Idea

1) Do not induce lasting hypoxemia because it causes magnification of the inflammation.

2) Do not perform prone position for patients with OIT indication, according to the criteria presented in this article. The prone position is good when it does not delay well-indicated intubation.

\section{Perform "IN TIME" orotracheal intubation if}

1) $\mathrm{O}_{2}$ saturation $\leq 92 \%(A B G)$ and $\mathrm{O}_{2}$ input $\geq 50 \%$ without supplementary $\mathrm{O}_{2}$. OR

2) $\mathrm{SatO} 2<90 \%$ without supplementary $\mathrm{O}_{2}$ (oximeter).

$O R$

3) $\mathrm{RR}>30$ breaths per minute.

Immediate orotracheal intubation

1) $\mathrm{OR} \mathrm{O}_{2} \mathrm{ABG}<75 \%$ without supplementary $\mathrm{O}_{2}$. $O R$

2) GLASGOW COMA SCORE $<8$ points.

$O R$

\section{3) CARDIAC ARREST.}

The criteria for "in time" OTI are rigid, but when associating $\mathrm{PaO}_{2} / \mathrm{FiO}_{2}$, we can see the patient is already in a ratio lower than 200, respiratory distress syndrome (Berlin's criteria. Hypoxemia: $\mathrm{PaO}_{2} / \mathrm{FiO}_{2} \leq 300$ : between 200 and 300; Moderate: between 100 and 200; Severe: less than 100).

In a previous article [32] [54] (Zanella and Galvão, 2021; Zanella, 2021), we explained that hypoxemia makes changes in the microenvironment, since the immune system acquired a tolerant status allowing neoplastic and autoimmune diseases, and a paralysis of the immunity by an inflammation that was magnified by angiogenesis secondary to hypoxemia.

${ }^{*}$ COVER-Me-UP: COVID-19 randomised trial of Methylprednisolone using pulse therapy.

Approved by the National Research Ethics Commission. Brazil.

Approved by the HSPE Research Ethics Committee.

\section{Acknowledgements}

\section{Hospital do Servidor Público Estadual}

Clinical manager of the HSPE: Dr. Andrea Lucia Ladeira de Almeida.

Your support allows us to grow up in the face of difficulties.

Head of the ICU-HSPE: Ederlon Alves de Carvalho REZENDE. By believing 
in a strict criterion, in which "in time" intubation is, first of all, part of an essential therapy for some COVID-19 patients.

To the HSPE Infectious Diseases physicians: Adriana Macedo Dell' Aquila, Antonio Mitihossi Nagamachi, Augusto Yamaguti, Caio Rosenthal, Carlos Armando de Ávila, Cibele Lefevre Correa Fonseca, Cinzia Trevisanello, Cristiano Melo Gamba, Davi Francisco Lopez, Durval Alex Gomes e Costa, João Silva de Mendonça, Marcelo Milleto Mostardeiro, Marina Keiko Kwabara Tsukumo, Marli Sasaki, Rosa Maria Barbosa, Thaís Guimarães, Vera Maria Coutinho de Moraes, Zilda Zuleima e Silva, Residents in Infectious Diseases: Amanda Fernandes Silva Takenaka, Ana Flavia Forato Pereira, Letícia Verona Martinis Costa, Marcela Gonsales Menis, Beatriz Turato Mendonça, Luisa Caracik de Camargo Andrade, Gabrielle Picanco Rilhas, Samylla Costa de Moura, Pedro Saliba e Borges, Rafael Corrêa Barros, Daniel Litardi Castorino.

Technical director of HSPE: Dr. Kátia Antunes.

Clinical director: Lilia Azzi Collet da Rocha Camargo.

\section{Consent to Participate}

According to the National Research Ethics Commission of the Federative Republic of Brazil-CNS Resolution No. 466 of 2012, this review does not require a consent form, as it does not present data that directly identify patients and because it is a theoretical research that it arises naturally from a professional practice that uses data that does not reveal the subjects/patients. Even so, the article is filed with the HSPE RESEARCH ETHICS COMMITTEE, via the Brazil research platform with approved dismissal.

\section{Consent to Publish}

Manuscript has approved by HSPE Research Ethics Committee.

\section{Availability of Data and Materials}

All data are available in the electronic medical record system of Hospital do Servidor Estadual (Sao Paulo-Brazil) and in the authors' research files.

\section{Author Contributions}

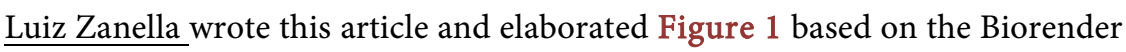
platform. He has been performing active participation in the management of COVID-19 patients. He wants to show that immune suppression in COVID-19 patients is responsible to reduced antibodies production.

Luciana Galvão realised (still in the beginning) that COVID-19 patients need different management to overcome COVID-19 and have been working hard to pass way her experience ahead.

We are Principal investigators "COVER-ME-UP" TRIAL (Methylprednisolone pulse).

Daniela Paraskevopoulos: reviewed all articles and analysed their characteris- 
tics.

Augusto Yamaguti: is the head of Infectious Diseases and coordinates all works that we have been performing.

\section{Conflicts of Interest}

The authors declare no conflicts of interest regarding the publication of this paper.

\section{References}

[1] Sheianov, M.V., Udalov, Y.D., Ochkin, S.S., Bashkov, A.N. and Samoilov, A.S. (2020) Pulse Therapy with Corticosteroids and Intravenous Immunoglobulin in the Management of Severe Tocilizumab-Resistant COVID-19: A Report of Three Clinical Cases. Cureus, 12, e9038. https://doi.org/10.7759/cureus.9038

[2] Edalatifard, M., Akhtari, M., Salehi, M., et al. (2020) Intravenous Methylprednisolone Pulse as a Treatment for Hospitalised Severe COVID-19 Patients: Results from a Randomised Controlled Clinical Trial. European Respiratory Journal, 56, Article ID: 2002808. https://doi.org/10.1183/13993003.02808-2020

[3] Mareev, V.Y., Orlova, Y.A., Pavlikova, E.P., Matskeplishvili, S., Krasnova, T.N. and Malahov, P.S. (2020) Steroid Pulse-Therapy in Patients with Coronavirus Pneumonia (COVID-19), Systemic Inflammation and Risk of Venous Thrombosis and Thromboembolism (Wayfarer Study). Kardiologiya, 60, 15-29.

https://doi.org/10.18087/cardio.2020.6.n1226

[4] Kiningham, K.K. (2007) Methylprednisolone. In: xPharm: The Comprehensive Pharmacology Reference, Elsevier, Amsterdam, 1-6. https://doi.org/10.1016/B978-008055232-3.62167-1

[5] Zaitsev, A.A., Golukhova, E.Z., Mamalyga, M.L., et al. (2020) Efficacy of Methylprednisolone Pulse Therapy in Patients with COVID-19. Clinical Microbiology and Antimicrobial Chemotherapy, 22, 88-91.

https://doi.org/10.36488/cmac.2020.2.88-91

[6] Gupta, S. and Kaplan, M. (2016) The Role of Neutrophils and NETosis in Autoimmune and Renal Diseases. Nature Reviews Nephrology, 12, 402-413. https://doi.org/10.1038/nrneph.2016.71

[7] Laforge, M., Elbim, C., Frère, C., et al. (2020) Tissue Damage from Neutrophil-Induced Oxidative Stress in COVID-19. Nature Reviews Immunology, 20, 515-516. https://doi.org/10.1038/s41577-020-0407-1

[8] Montecucco, F., Bauer, I., Braunersreuther, V., et al. (2013) Inhibition of Nicotinamide Phosphoribosyltransferase Reduces Neutrophil-Mediated Injury in Myocardial Infarction. Antioxidants and Redox Signaling, 18, 630-641. https://doi.org/10.1089/ars.2011.4487

[9] Ruiz-Irastorza, G., Pijoan, J.-I., Bereciartua, E., et al. (2020) Second Week MethylPrednisolone Pulses Improve Prognosis in Patients with Severe Coronavirus Disease 2019 Pneumonia: An Observational Comparative Study Using Routine Care Data. PLoS ONE, 15, e0239401. https://doi.org/10.1371/journal.pone.0239401

[10] Tamura, K., Nishioka, S., Tamura, N., Saito, Z. and Kuwano, K. (2020) Successful Treatment with Methyl-Prednisolone Pulses for the Late Phase of COVID-19 with Respiratory Failure: A Single-Center Case Series. Respiratory Medicine Case Reports, 31, Article ID: 101318. https://doi.org/10.1016/j.rmcr.2020.101318

[11] Espinosa-Solano, M., Gonzalez-Vergara, D., Ferrer-Galvan, M., et al. (2021) Re- 
peated Pulses of Methyl-Prednisolone in Adults Hospitalized With COVID-19 Pneumonia and Acute Respiratory Distress Syndrome: A Preliminary Before-After Study (CortiCOVID Study). Open Respiratory Archives, 3, Article ID: 100086. https://doi.org/10.1016/j.opresp.2021.100086

[12] Sauñe, P.M., Bryce-Alberti, M., Portmann-Baracco, A.S. and Accinelli, R.A. (2020) Methylprednisolone Pulse Therapy: An Alternative Management of Severe COVID-19. Respiratory Medicine Case Reports, 31, Article ID: 101221. https://doi.org/10.1016/j.rmcr.2020.101221

[13] Salton, F., Confalonieri, P., Meduri, G.U., et al. (2020) Prolonged Low-Dose Methylprednisolone in Patients with Severe COVID-19 Pneumonia. Open Forum Infectious Diseases, 7, ofaa421. https://doi.org/10.1101/2020.06.17.20134031

[14] Motte, L.D., Kehlet, H., Vogt, K., et al. (2014) Preoperative Methylprednisolone Enhances Recovery after Endovascular Aortic Repair: A Randomized, Double-Blind, Placebo-Controlled Clinical Trial. Annals of Surgery, 260, 540-548. https://doi.org/10.1097/SLA.0000000000000895

[15] Lopez Zuniga, M.A., Moreno-Moral, A., Ocana-Granados, A., et al. (2021) High-Dose Corticosteroid Pulse Therapy Increases the Survival Rate in COVID-19 Patients at Risk of Hyper-Inflammatory Response. PLOS ONE, 16, e0243964. https://doi.org/10.1371/journal.pone.0243964

[16] Goyal, A., Saigal, S., Joshi, A., et al. (2020) Whether Early Pulse Steroid Dose Is Associated with Lower Mortality in COVID-19 Critically Ill Patients-An Exploratory Retrospective Chart Review.

[17] Zha, L., Li, S., Pan, L., et al. (2020) Corticosteroid Treatment of Patients with Coronavirus Disease 2019 (COVID-19). Medical Journal of Australia, 212, 416-420. https://doi.org/10.5694/mja2.50577

[18] Lu, X., Chen, T., Wang, Y., Wang, J. and Yan, F. (2020) Adjuvant Corticosteroid Therapy for Critically Ill Patients with COVID-19. Critical Care, 24, 241.

[19] Cusacovich, I., Aparisi, A., Marcos, M., et al. (2021) Corticosteroid Pulses for Hospitalized Patients with COVID-19: Effects on Mortality. Mediators of Inflammation, 2021, Article ID: 6637227. https://doi.org/10.1155/2021/6637227

[20] Ho, J.C., Ooi, G.C., Mok, T.Y., et al. (2003) High-Dose Pulse versus Nonpulse Corticosteroid Regimens in Severe Acute Respiratory Syndrome. American Journal of Respiratory and Critical Care Medicine, 168, 1449-1456.

https://doi.org/10.1164/rccm.200306-766OC

[21] Bartoletti, M., Marconi, L., Scudeller, L., et al. (2021) Efficacy of Corticosteroid Treatment for Hospitalized Patients with Severe COVID-19: A Multicentre Study. Clinical Microbiology and Infection, 27, 105-111.

https://doi.org/10.1016/j.cmi.2020.09.014

[22] So, C., Ro, S., Murakami, M., Imai, R. and Jinta, T. (2020) High-Dose, Short-Term Corticosteroids for ARDS Caused by COVID-19: A Case Series. Respirology Case Reports, 8, e00596. https://doi.org/10.1002/rcr2.596

[23] Monedero, P., Gea, A., Castro, P., et al. (2021) Early Corticosteroids Are Associated with Lower Mortality in Critically Ill Patients with COVID-19: A Cohort Study. Critical Care, 25, 2. https://doi.org/10.1186/s13054-020-03422-3

[24] Ahmad, S., Sohail, A., Abubakar, M. and Chishti, S. (2020) Corticosteroids in COVID-19 Management-A Systematic Review and Meta-Analysis Based on Recent Evidence. Biomedical Journal of Scientific \& Technical Research, 32, 25159-25167.

[25] van den Eynde, E., Gasch, O., Oliva, J.C., et al. (2021) Corticosteroids and Tocilizumab Reduce In-Hospital Mortality in Severe COVID-19 Pneumonia: A 
Retrospective Study in a Spanish Hospital. Infectious Diseases, 53, 291-302. https://doi.org/10.1080/23744235.2021.1884286

[26] Rodríguez-Baño, J., Pachón, J., Carratalà, J., et al. (2021) Treatment with Tocilizumab or Corticosteroids for COVID-19 Patients with Hyperinflammatory State: A Multicentre Cohort Study (SAM-COVID-19). Clinical Microbiology and Infection, 27, 244-252. https://doi.org/10.1016/j.cmi.2020.08.010

[27] Ma, S., Xu, C., Liu, S., et al. (2021) Efficacy and Safety of Systematic Corticosteroids among Severe COVID-19 Patients: A Systematic Review and Meta-Analysis of Randomized Controlled Trials. Signal Transduction and Targeted Therapy, 6, 1-7. https://doi.org/10.1038/s41392-021-00521-7

[28] Edara, L., Suvvari, T.K. and Kutikuppala, L.V.S. (2020) High Dose Steroid Therapy to Prevent Severe Hypoxia in COVID-19 Patients: A Potential Solution for Low Resource Clinical Setting. Cureus, 12, e12330. https://doi.org/10.7759/cureus.12330

[29] Bayrak, M. and Cadirci, K. (2021) Successful Pulsed Methylprednisolone and Convalescent Plasma Treatment in a Case of a Renal Transplant Recipient with COVID-19 Positive Pneumonia: A Case Report. The Pan African Medical Journal, 38, 273.

[30] Conticini, E., Franchi, F., Bennett, D., et al. (2020) High Dosage of Methylprednisolone as a Rescue, Second-Line Treatment in COVID-19 Patients Who Failed to Respond to Tocilizumab. Annals of the Rheumatic Diseases. . https://doi.org/10.1136/annrheumdis-2020-218761

[31] Zhao, Z., Zhang, F., Xu, M., et al. (2003) Description and Clinical Treatment of an Early Outbreak of Severe Acute Respiratory Syndrome (SARS) in Guangzhou, PR China. Journal of Medical Microbiology, 52, 715-720. https://doi.org/10.1099/jmm.0.05320-0

[32] Barros D’Elia Zanella, L.G.F.A. and de Lima Galvão, L. (2021) The COVID-19 Burden or Tryptophan Syndrome: Autoimmunity, Immunoparalysis and Tolerance in a Tumorigenic Environment. Journal of Infectious Diseases and Epidemiology, 7, 195.

[33] Ping, W.N. (2006) Aging of the Immune System: How Much Can the Adaptive Immune System Adapt? Immunity, 24, 495-499.

https://doi.org/10.1016/j.immuni.2006.05.001

[34] Green, W.D. and Beck, M.A. (2017) Obesity Impairs the Adaptive Immune Response to Influenza Virus. Annals of the American Thoracic Society, 14, S406-S409. https://doi.org/10.1513/AnnalsATS.201706-447AW

[35] Thierry, A.R. and Roch, B. (2020) SARS-CoV2 May Evade Innate Immune Response, Causing Uncontrolled Neutrophil Extracellular Traps Formation and Multi-Organ Failure. Clinical Science (London, England: 1979), 134, 1295-1300. https://doi.org/10.1042/CS20200531

[36] Shah, V.K., Firmal, P., Alam, A., Ganguly, D. and Chattopadhyay, S. (2020) Overview of Immune Response during SARS-CoV-2 Infection: Lessons from the Past. Frontiers in Immunology, 11, 1949. https://doi.org/10.3389/fimmu.2020.01949

[37] Borczuk, A.C., Salvatore, S.P., Seshan, S.V., et al. (2020) COVID-19 Pulmonary Pathology: A Multi-Institutional Autopsy Cohort from Italy and New York City. Modern Pathology, 33, 2156-2168. https://doi.org/10.1038/s41379-020-00661-1

[38] Bozzani, A., Arici, V., Tavazzi, G., et al. (2020) Acute Arterial and Deep Venous Thromboembolism in COVID-19 Patients: Risk Factors and Personalized Therapy. Surgery (United States), 168, 987-992. https://doi.org/10.1016/j.surg.2020.09.009

[39] Pons, S., Fodil, S., Azoulay, E. and Zafrani, L. (2020) The Vascular Endothelium: The Cornerstone of Organ Dysfunction in Severe SARS-CoV-2 Infection. Critical 
Care, 24, 1116-1120. https://doi.org/10.1186/s13054-020-03062-7

[40] Klok, F.A., Kruip, M.J.H.A., van der Meer, N.J.M., et al. (2020) Incidence of Thrombotic Complications in Critically Ill ICU Patients with COVID-19. Thrombosis Research, 191, 145-147. https://doi.org/10.1016/j.thromres.2020.04.013

[41] Giannis, D., Ziogas, I.A. and Gianni, P. (2020) Coagulation Disorders in Coronavirus Infected Patients: COVID-19, SARS-CoV-1, MERS-CoV and Lessons from the Past. Journal of Clinical Virology, 127, Article ID: 104362. https://doi.org/10.1016/j.jcv.2020.104362

[42] Llitjos, J.F., Leclerc, M., Chochois, C., et al. (2020) High Incidence of Venous Thromboembolic Events in Anticoagulated Severe COVID-19 Patients. Journal of Thrombosis and Haemostasis, 18, 1743-1746. https://doi.org/10.1111/jth.14869

[43] Tan, B.K., Mainbourg, S., Friggeri, A., et al. (2021) Arterial and Venous Thromboembolism in COVID-19: A Study-Level Meta-Analysis. Thorax.

https://doi.org/10.1136/thoraxjnl-2020-215383

[44] Buja, L.M., Wolf, D., Zhao, B., et al. (2020) The Emerging Spectrum of Cardiopulmonary Pathology of the Coronavirus Disease 2019 (COVID-19): Report of $3 \mathrm{Au}$ topsies from Houston, Texas, and Review of Autopsy Findings from Other United States Cities. Cardiovascular Pathology, 48, Article ID: 107233. https://doi.org/10.1016/j.carpath.2020.107233

[45] Sperhake, J.P. (2020) Autopsies of COVID-19 Deceased? Absolutely! Legal Medicine, 47, Article ID: 101769. https://doi.org/10.1016/j.legalmed.2020.101769

[46] McMullen, P., Pytel, P., Snyder, A., et al. (2021) A Series of COVID-19 Autopsies with Clinical and Pathologic Comparisons to Both Seasonal and Pandemic Influenza. Journal of Pathology: Clinical Research. https://doi.org/10.1002/cjp2.220

[47] Ritchie, A.I. and Singanayagam, A. (2020) Immunosuppression for Hyperinflammation in COVID-19: A Double-Edged Sword? The Lancet, 395, 1111.

https://doi.org/10.1016/S0140-6736(20)30691-7

[48] Omran, H.M. and Almaliki, M.S. (2020) Influence of NAD+ as an Ageing-Related Immunomodulator on COVID 19 Infection: A Hypothesis. Journal of Infection and Public Health, 13, 1196-1201. https://doi.org/10.1016/j.jiph.2020.06.004

[49] Kazancioglu, S., Meric Yilmaz, F., Bastug, A., et al. (2021) Lymphocyte Subset Alteration and Monocyte CD4 Expression Reduction in Patients with Severe COVID-19. Viral Immunology, 34, 342-351.

[50] Bost, P., Sanctis, F., Canè, S., et al. (2021) Deciphering the State of Immune Silence in Fatal COVID-19 Patients. Nature Communications, 12, 1428. https://doi.org/10.1038/s41467-021-21702-6

[51] Rokni, M., Ahmadikia, K., Asghari, S., Mashaei, S. and Hassanali, F. (2020) Comparison of Clinical, Para-Clinical and Laboratory Findings in Survived and Deceased Patients with COVID-19: Diagnostic Role of Inflammatory Indications in Determining the Severity of Illness. BMC Infectious Diseases, 20, Article No. 869. https://doi.org/10.1186/s12879-020-05540-3

[52] Bellesi, S., Metafuni, E., Hohaus, S., et al. (2020) Increased CD95 (Fas) and PD-1 Expression in Peripheral Blood T Lymphocytes in COVID-19 Patients. British Journal of Haematology, 191, 207-211. https://doi.org/10.1111/bjh.17034

[53] Rha, M.-S., Jeong, H.W., Ko, J.-H., et al. (2021) PD-1-Expressing SARS-CoV-2-Specific CD8+ T Cells Are Not Exhausted, but Functional in Patients with COVID-19. Immunity, 54, 44-52.e3. https://doi.org/10.1016/j.immuni.2020.12.002

[54] Barros D’Elia Zanella, L.G.F.A. (2021) NAD/NADH+, Tryptophan Metabolism and 
Thermogenesis like Hecatomb: The Keys to Understanding COVID-19 Uniting Theory and Clinical Practice.

[55] Bg, S., Gosavi, S., Ananda Rao, A., et al. (2021) Neutrophil-to-Lymphocyte, Lymphocyte-to-Monocyte, and Platelet-to-Lymphocyte Ratios: Prognostic Significance in COVID-19. Cureus, 13, e12622. https://doi.org/10.7759/cureus.12622

[56] Sierzega, M., Lenart, M., Rutkowska, M., et al. (2017) Preoperative Neutrophil-Lymphocyte and Lymphocyte-Monocyte Ratios Reflect Immune Cell Population Rearrangement in Resectable Pancreatic Cancer. Annals of Surgical Oncology, 24, 808-815. https://doi.org/10.1245/s10434-016-5634-0

[57] Seyit, M., Avci, E., Nar, R., et al. (2020) Neutrophil to Lymphocyte Ratio, Lymphocyte to Monocyte Ratio and Platelet to Lymphocyte Ratio to Predict the Severity of COVID-19. American Journal of Emergency Medicine, 40, 110-114.

https://doi.org/10.1016/j.ajem.2020.12.069

[58] Chan, A.S. and Rout, A. (2020) Use of Neutrophil-to-Lymphocyte and Platelet-to-Lymphocyte Ratios in COVID-19. Journal of Clinical Medicine Research, 12, 448-453. https://doi.org/10.14740/jocmr4240

[59] Imran, M.M., Ahmad, U., Usman, U., Ali, M., Shaukat, A. and Gul, N. (2021) Neutrophil/Lymphocyte Ratio-A Marker of COVID-19 Pneumonia Severity. International Journal of Clinical Practice, 75, e13698. https://doi.org/10.1111/ijcp.13698

[60] Simadibrata, D.M., Pandhita, B.A.W., Ananta, M.E. and Tango, T. (2020) Platelet-to-Lymphocyte Ratio, a Novel Biomarker to Predict the Severity of COVID-19 Patients: A Systematic Review and Meta-Analysis. Journal of the Intensive Care Society. https://doi.org/10.1101/2020.08.21.20166355

[61] Wang, X., Li, X., Shang, Y., et al. (2020) Ratios of Neutrophil-to-Lymphocyte and Platelet-to-Lymphocyte Predict All-Cause Mortality in Inpatients with Coronavirus Disease 2019 (COVID-19): A Retrospective Cohort Study in a Single Medical Center. Epidemiology and Infection, 148, e211. https://doi.org/10.1017/S0950268820002071

[62] Güneysu, F., Guner, N.G., Erdem, A.F., Durmus, E., Durgun, Y. and Yurumez, Y. (2020) Can Covid-19 Mortality Be Predicted in the Emergency Room? Journal of the College of Physicians and Surgeons Pakistan, 30, 928-932.

https://doi.org/10.29271/jcpsp.2020.09.928 


\section{Abbreviations}

T2DM = Type 2 Diabetes mellitus.

$\mathrm{BMI}=$ body mass index.

$\mathrm{NET}=$ neutrophil extracellular traps.

NETose $=$ a type of regulated cell death dependent on the formation of neutrophil extracellular traps (NET).

\section{Appendix}

\section{COVER-ME-UP Elegibility and Criteria for MTP Pulse}

1) General criteria for inclusion in the study (eligibility)

- Patient be admitted to hospital.

- Sars-CoV-2 laboratory-confirmed or clinically suspected.

- No medical condition that could place the patient at risk in the judgment of the responsible physician.

A) - Inclusion criteria:

- age 18 years or older.

- according to the criteria for clinical diagnosis and etiological diagnosis of new pneumonia by a coronavirus (COVID-19) or Hyperinflammatory Syndrome.

- admitted to the general wards of HSPE or collaborating institutions.

- be able to sign the informed consent.

B) - Exclusion criteria:

- Severe immunosuppression of the judgment of physicians who assess the patient concerning the treatment benefit.

- Non-acceptance by the family member or legal guardian of the use of Methylprednisolone in the form of pulse therapy.

- Summary contraindication to the use of corticosteroids.

- Patients are intolerant or allergic to any therapeutic agents used in this research.

- Pregnant or lactating women.

- Positive procalcitonin (if we get release).

- Acute myocardial infarction confirmed by abnormal troponin test and electrocardiogram (viral myocarditis does not contraindicate).

- Active neoplasms and received any immunosuppressive agents.

Hypertension (hypertension), uncontrolled diabetes mellitus (DM), gastrointestinal problems, or a history of gastrointestinal bleeding (pulse may be performed if upper endoscopy does not find active lesions).

C) - Criteria for patients over 80 years old

Every patient over 80 years old will be evaluated by the Geriatric Clinic for pulse release with Methylprednisolone, as the patient's degree of independence will be assessed, as well as their cognitive and the pros and cons of pulse therapy for the patient at this stage of life, considering the limitations that attack.

COVER-ME-UP Protocol: Criteria for pulse MTP immediately after the 


\section{viraemic phase or early pulmonary phase}

Patients have a diagnosis of COVID-19 (I) and concomitant evidence of Cytokine Storm Syndrome (II) and preferentially with $\mathrm{PaO}_{2} / \mathrm{FiO}_{2}>200$.

\section{I) COVID-19 Diagnosis:}

A) RT-PCR-SARS-COV-2 positive or

B) Consider the evaluation of the IgM class with the presence or not of IgG, associated with the clinical and tomographic image compatible with COVID-19, and negative RT-PCR-Sars-CoV-2 exam: keep the note on the CT OR

C) high clinical probability (desaturation below $90 \%$ in arterial blood gases, excluding other causes) in the presence of negative $\mathrm{A}$ and $\mathrm{B}$

D) CT image result compatible with CORADS 3, 4 OR 5.

II) Definition of Cytokine Storm Syndrome:

A) Patient with oxygen saturation (Sat $\mathrm{O} 2)<94 \%$ at rest (with $\mathrm{O}_{2}$ catheter at maximum $6 \mathrm{~L} / \mathrm{min}$ flow) OR with blood oxygen saturation $<90 \%$ by the oximeter.

OR

B) Mild tachypnoea-respiratory rate $>18 \mathrm{bpm}$ (although the definition used $\mathrm{RR}>30$, for inclusion, we need that the patient is in good clinical condition and not deteriorated in case of a respiratory rate greater than or equal to 30 ).

AND

C) Have two altered BIOMARKERS: C-reactive protein greater than 10, ferritin and d-dimer with or without leucocytosis, preferably IL-6 if available.

However, consider PCR $<10$ avoiding the cytokine storm.

First Author's subjective considerations

We have one of the biggest challenges, which is the management of the COVID-19 patient, because the SARS-CoV-2 elaborates a disease that has similar characteristics between people and that, at the same time, elaborates specifics for each infected person, making its evaluation difficult, unique and detailed for each patient. Good assessment requires a careful and, at the same time, technical look that allows the physician to differentiate the singularities to direct the standard and individualized treatment correctly. Corticosteroids in high dose have a fundamental role in COVID-19, but it receives prejudice from all sides, and this fact is since we do not use science to seek answers, but instead because of subjectivism loaded with self-knowledge that is often based on mistaken concepts. Demonizing a drug based on wrong concepts and prejudice creates a risk of discarding a low-cost drug with easy access to the people. Methylprednisolone, Prednisolone, Dexamethasone and Prednisolone are more resolute drugs, if they are used correctly and appropriately. A small cohort of 18 patients, which data have not published yet-was submitted to a pulse of Prednisolone $400 \mathrm{mg}$ (5 tablets every 2 minutes, totalling $600 \mathrm{mg}$ ), receiving the dose for four days from the sixth or seventh day of the onset of symptoms as reported by the patients. Among patients were comorbidities, some of them with predictors to severe disease: $\mathrm{HIV}+$ patients with $\mathrm{CD} 4+>500$ and undetectable viral load, obese-above overweight and abnormal or excessive fat accumulation calculated 
by Body mass index (BMI). None of them required orotracheal intubation (data to be published soon), and even the obese had the inflammatory storm aborted. Recovering from steroid immunosuppression is much easier than the difficult recovery from the immunoparalysis in COVID-19 due to the cytokine storm.

In summary, this article discusses the extraordinary Iranian work by Maryan Edalatifard and colleagues that brings to light the possibility of preventing so many deaths if corticosteroids are used in time. The Middle East study explains that we are late and wasting time while many deaths happen. Although corticosteroids have their side effects, we do not yet have a better and affordable drug, and we are experienced in dealing with the side effects of corticosteroids. I quote that, once again, Iranian experience brings to us concepts in the face of science, which should be free of interest policies and prejudices to serve as a mechanism for the growth and improvement of humanity.

Criteria for Patient Hospitalization, Pulse of Methylprednisolone and Orotracheal Intubation (an author observation based on medical literature and clinical practice).

Complementing this work, I propose an assessment of hospitalization and intubation criteria, based on the medical practice of 1 year and a half of patient management COVID-19, whose evolution of knowledge is closely related to daily study (and it continues to be so). Finally, I reaffirm that sustained hypoxemia is terrible for patients, especially those who are obese and people with diabetes with insulin resistance, and to leave them in anaerobic conditions is to create a catastrophic inflammation that is difficult to manage (data on this analysis will be available and published soon, confirming this clinical approach.).

\section{Assessment in the Emergency Room}

(Protocol suggested by the fist author)

I) Asymptomatic People: perform RT-PCR if no symptoms but with existing epidemiological history (within 7 - 14 days of exposure, considering viral kinetics)

\section{General Criteria of Hospitalization}

II) Symptomatic People

\section{No comorbidities and age under 60 years:}

A) Without admission criteria ${ }^{*}$ and before D6 = discharge with dipyrone or paracetamol and Prednisolone (Figure 4). Orientation to return to the hospital if saturation $<95$ at home or respiratory distress.

B) With admission criteria:

i) and at least in day 6 (D6) from symptom onset: Pulse with Methylprednisolone.

ii) If T $<$ D6: hospitalize and wait for D6 to pulse.

\section{Comorbidities and age as severity predictors*}

A) Without clinical criteria for admission and T > D8: discharge with symptoms and Prednisolone $1 \mathrm{mg} / \mathrm{kg} /$ day for 3 days. Orientation to return to the hospital if saturation $<95 \%$ at home or respiratory distress. 
B) If $\mathrm{T}<\mathrm{D} 6$ without symptoms or minor criteria for hospitalization: hospitalization and wait for $\mathrm{D} 6$ and or CRP $>10 \mathrm{mg} / \mathrm{L}$ to pulse

C) With clinical and or laboratorial admission criteria and at least in day 6 (D6) from symptom onset: Pulse with MTP.

D) With clinical and or laboratorial admission criteria and $\mathrm{T}>\mathrm{D} 8$ from symptom onset AND CRP $>10 \mathrm{mg} / \mathrm{L}$ : Pulse with MTP at least one time and evaluates if is necessary complete 3 days of pulse.

IF CRP $<10 \mathrm{mg} / \mathrm{L}$ and major criteria for hospitalization: pulse with MTP.

3. Typical Manifestations with an Image in Ground Grass and Clinical Symptoms

- Altered BMI (including overweight)

- Type 2 Diabetes mellitus

- Elderly $>60$ years old, worse if older than 65 years.

- Hypertension

- Cardiologic disease

- HIV CD4+ > 500

- Untreated asthma.

In theory, these patients have bone marrow standard and immune system intact or close to normal and present inflammatory cells capable of inflaming the lungs and forming a typical image and causing symptoms.

\section{Atypical Manifestations without Characteristic Image and} Oligosymptomatic Disease

- Renal chronic disease.

- Cirrhosis.

- COPD.

- Immunosuppressed by chemotherapy.

- Solid-organ neoplasm.

- Hematologic neoplasm.

- HIV with CD4+< 500.

- Rheumatologic patients using immunosuppressants.

- Hypothyroidism.

In theory, these patients have poorly responsive bone marrow or are blocked by immunosuppressive or immunosuppressive drugs. They usually present oligosymptomatic conditions, confusing, for example, as in cirrhotic, whose decompensation with hepatic encephalopathy was triggered by inflammation and hypoxemia in COVID-19. These patients are often not diagnosed with COVID-19. Pulmonary images are also frustrating, as in COPD patients.

4.1. Pregnant women first and second trimesters: little symptomatic and with a placenta susceptible to thrombosis. Constantly evaluate the patient with the Obstetrician who is accompanying her and jointly decide on using a dose of up to $1 \mathrm{mg} / \mathrm{kg} / \mathrm{day}$. Always perform obstetric ultrasound in case of emergency and quantify amniotic fluid. Third trimester: the placenta is older than the beginning of pregnancy, and the woman is more symptomatic than she could be in the first and second trimesters. 


\subsection{Pregnant women and the third trimester:}

If symptomatic and between D6 and D8: up to $1 \mathrm{mg} / \mathrm{kg} /$ day of MTP for three days with sequential weaning $40 \mathrm{mg}$ for three days, $20 \mathrm{mg}$ for three days, $10 \mathrm{mg}$ for three days and $5 \mathrm{mg}$ for three days. Third trimester in the possibility of pregnancy resolution. Start MTP $1 \mathrm{mg} / \mathrm{kg} /$ day AND: AFTER RESOLUTION OF DELIVERY (Obstetrician's indication): a) Perform non-contrast chest computed tomography immediately. b) Intensive Care Unit or Intermediate Care Unit and management of pre-eclampsialeclampsia, management of primary gestational diabetes or diabetes caused by COVID-19. Management of primary gestational hypertension or caused by COVID-19. Pulse if the patient has had symptoms for more than six days or if a tomography shows involvement more significant than $50 \%$, or if $\mathrm{O}_{2}$ saturation is less than $94 \%$ using an $\mathrm{O}_{2}$ catheter in up to $6 \mathrm{~L} /$ minute. The placenta is protective for the woman (article submitted) and, after the delivery has been resolved, the woman can rapidly progress to SARS-CoV-2 Respiratory Distress Syndrome

\section{Adjuvant Therapy (Suggested Based on Probable Pathophysiology but not Yet Proven Fully)}

- Complex B vitamin due to B3 depletion via tryptophan depletion.

- Atorvastatin $80 \mathrm{mg}$ for at least 20 days due to oxidative stress.

- Establish good nutrition with amino acid replacement.

- Citalopram $40 \mathrm{mg}$ for inhibition of platelet aggregation and serotonin conservation.

- ASA acetylsalicylic acid $100 \mathrm{mg}$ once daily to inhibit platelet activation.

- Prophylactic heparin and, If thrombosis is detected, expand to the total dose.

- N-acetylcysteine $600 \mathrm{mg}$ daily due to oxidative stress and glutathione-dependent redox imbalance caused by high glucose/high palmitic acid.

- Insulin in continuous infusion pump if hyperthermia.

\section{General Evaluation}

For patients who arrive late at the Emergency Room, that is, with $\mathrm{C}$ reactive Protein greater than $10 \mathrm{U} / \mathrm{L}$, or respiratory distress or respiratory rate greater than 30 incursions per minute or Oxygen saturation less than $94 \%$ with a catheter $\mathrm{O}_{2}$ in a maximum of $6 \mathrm{~L} /$ minute:

i) Some Russian protocols present in the references of this article even associate immunoglobulin with good results, but orotracheal intubation should not be postponed, especially for obese and diabetic patients.

ii) Assess blood pressure, disglycemia and make the necessary corrections.

iii) Pay attention to changes in the level of consciousness. Evaluate to rule out acute stroke. If ruled out, assume the clinical presentation caused by cytokine storm and: MTP pulse is indicated.

iv) Pay attention to how lymphopenia the patient was on the day of sudden $\mathrm{C}$ Reactive Protein elevation or the first day of a storm. In these cases, the pulse may be too immunosuppressant for the patient who is already immunoparalysis. For this question we still must carry out a lot more research. But, from experi- 
ence, removing the patient from inflammatory status by COVID-19 seems to have more benefit than harm. Consider changes on time (less days, e.g.) if one or two pulses have a good response.

v) Reactivation of latent fungal and viral diseases and mycobacteria: lymphopenia allows, in some cases, the reactivation of these latent diseases is so intense. The subacute phase is not always a pure result of COVID-19, we may have an association of COVID-19 and a reactivated latent disease. Case-by-case assessment and care.

vi) Urinary tract infection: often a family member's complaint is that the elderly person is in hypoactive delirium. Infectious screening was carried out in the hospital, and urine with leukocyturia, haematuria, proteinuria was found. Remember that these are renal changes in COVID-19, so every urinary symptom should be well evaluated and have a pulmonary image on tomography to rule out COVID-19. It seems excessive, but it is common for patients hospitalized for urinary tract infection to develop respiratory failure within 3 or 4 days after admission.

\section{Psychiatric Symptoms}

COVID-19 allows a deficit of tryptophan that depletes serotonin, dopamine, melatonin and vitamin $\mathrm{B} 3(\mathrm{NAD} / \mathrm{NADH}+)$. Sudden depletion has brought a plethora of acute symptoms such as opening of COVID-19. Very carefully evaluate a person without a psychiatric history and investigate this acute condition with pulmonary image. Decompensations in chronic cases also occur and deserve pulmonary imaging.

Do not use antagonists of the dopaminergic and serotoninergic pathways. (Article in submission).

\section{Avoid Hypoxemia}

Especially in obese and diabetic patients, the hypoxemic status should not be prolonged. The difficulty in sedating these patients, as well as immunosuppression, is directly proportional to the time of exposure to hypoxemia. Always intubate these patients on time. The others can perform other control mechanisms such as non-invasive ventilation as long as a well-indicated intubation is not postponed.

\section{Hospitalization criteria}

It should be noted that COVID-19 is a biphasic disease (very reminiscent of yellow fever and Leptospirosis) with the first inflammatory phase mediated by the pathogen, proceeding to a defervescence phase. The third phase is immune-mediated (toxaemic) which, in the case of COVID-19, has the worst outcome in those people with inflammatory comorbidities such as Diabetes, any degree of obesity and/or insulin resistance and age over 60 years, since aging is also inflammatory. With these considerations, we take as the basis of criteria for hospitalization:

\section{Criteria of Hospitaization}

Any patients with: 


\section{Clinical and Image Criteria (Independent of Comorbidities)}

\section{1) MAJOR criteria}

i) Lung image with more than $50 \%$ of lesion by SARS-CoV-2 or

ii) $\mathrm{O}_{2}$ saturation $<95 \%$ without $\mathrm{O}_{2}$ supplementation if up to D6

iii) Respiratory distress with mild tachypnoea with a respiratory rate greater than 25 breaths per minute or

iv) Any changes in the level of consciousness or

v) Any decompensation of comorbidities.

\subsection{MINOR criteria*}

- Lung image with less than $50 \%$ of lesion by SARS-CoV-2

- fever

- dry cough

- tiredness

- myalgia

- sore throat

- diarrhoea

- conjunctivitis

- headache

- loss of taste or smell

- skin rash or discoloration of fingers or toes

- skin rash

${ }^{*}$ Acute myocardial infarction, stroke, thrombosis and acute abdomen should follow the flow of specialties considering as a hypothesis, among the classics, COVID-19.

${ }^{*}$ Meningoencephalitis. should be evaluated considering screening for classical aetiologies, adding viral reactivation, for example due to immunosuppression by COVID-19.

${ }^{* * *}$ Falls from standing height. This type of trauma has been prevalent in orthopaedic emergency. The main causes should be investigated, as well as hypoxemia caused by COVID-19 or delirium secondary to COVID-19.

\section{Comorbidities Criteria (Imperative Criteria)}

i) Type II diabetic (T2DM) and/or

ii) Patients from overweight (BMI $\geq 25 \mathrm{~kg} / \mathrm{m}^{2}$ ) and/or

iii) People equal or over 65 years old ${ }^{*}{ }^{*}$ With at least one comorbidity

Other comorbidities or age $<65$ years to consider priority laboratory and clinical criteria.

Hematologic neoplasms or people who use T-cell immunosuppressants necessarily require hospitalization, as these patients can present extensive lesions since there are not abundant cytotoxic lymphocytes to act against the virus. Perform RT-PCR and or antigen on admission, and if $D>$ or equal D6, perform another RT-PCR. If the second RT-PCR (if the first was performed at admission and before $D=6)$ is negative and computerized tomography $(C T)$ shows lung injury greater than or equal to 50\%, consider pulse with $250 \mathrm{mg}$ of Methylpred- 
nisolone. Perform CT on admission and on worsening of symptoms.

Consider the same idea in the management of HIV patients with $C D 4+<500$ cells/ $\mathrm{mm}^{3}$.

In the absence of the above exams, consider chest $X$-ray progression and worsening of symptoms and: if $\mathrm{O}_{2}$ Saturation is less than or equal to $93 \%$, consider taking Methylprednisolone $1 \mathrm{mg} / \mathrm{kg} /$ day and consider pulsing with $250 \mathrm{mg}$ if there was an improvement in clinical and laboratory parameters with the dose of Methylprednisolone $1 \mathrm{mg} / \mathrm{kg} /$ day. Assess daily the need to perform three days of pulse therapy.

Cirrhotic patients with chronic kidney disease follow clinical and laboratory parameters as priorities and always perform a chest tomography.

Note: in a pandemic period, do not discard COVID-19 facing a bilateral image either on $X$-ray or CT. Consider urine assessment as an aid in the diagnostic workup. Hardly other type of pneumonia follows with super-assembled kidney damage. In COVID-19, haematuria, leukocyturia, presence of proteinuria and sometimes cylindruria are alterations seen in renal injury by SARS-CoV-2.

\section{Laboratory Criteria}

3.1. Major criteria:

i) $\mathrm{CRP}>10 \mathrm{U} / \mathrm{L}$.

ii) $\mathrm{LDH}>250 \mathrm{U} / \mathrm{L}$.

iii) Arterial blood gases (at E.R. with no PEEP).

Mild $200-300$ (mortality 27\%) = hospitalization.

Moderate $100-200($ mortality $32 \%)=$ hospitalization.

Severe $<100(45 \%$ mortality $)=$ hospitalization .

iv) Ratio: neutrophils/lymphocytes (RNL) [55]-[61].

v) Platelet/lymphocyte ratio (PLR) [60] [61] [62].

Suggested cut-off 180. As a new inflammatory index, the PLR may reflect the infection and factor aggregation. The PLR of patients means the degree of cytokine storm, which might provide a new indicator in the monitoring in patients with COVID-19.).

vi) Monocyte/lymphocyte ratio (RML)

Suggested cut-off values: $5.12 \mathrm{~K} / \mu \mathrm{l}$ for neutrophil, $1.12 \mathrm{~K} / \mu \mathrm{L}$ for lymphocyte, $67.78 \mathrm{mg} / \mathrm{dL}$ for CRP, 3.9 for NLR, and 148.85 for PLR, based on Fatih Güneysu et.al work.

An increase in apoptosis of lymphocytes leads to lymphopenia and elevated thrombopoietin (THPO) promotes megakaryocyte production. The reflections of these inflammatory changes can be vital in gauging the progression of the disease.

vi) Urine assessment ${ }^{*}$ : new and rising proteinuria (daily assessment).

zero + observe; $+4+=$ minimal injury $=$ admit and observe; ++ risk of severity $=$ hospitalization and intensifying care; +++ and $++++/ 4+$ criteria for ICU.

${ }^{*}$ patients with previous kidney damage makes the test more difficult, but continuous assessment may show an important evolution in urinary protein content. 


\subsection{Minor Criteria}

i) AST and ALT $>2 \times$ basal value.

ii) $\mathrm{CPR}>$ basal value.

iii) Electrolyte changes that may be symptomatic or put the patient at risk of heart attack.

iv) Urea and creatinine changes.

v) $\mathrm{CPK}>$ basal value.

vi) $\mathrm{D}$-dimer $>$ basal value.

vii) Hemogram with leukocytosis or leukopenia.

\section{Hospitalization if:}

- Major and imperative criteria: one is enough

i) One clinical or image major criterium is enough.

ii) One laboratorial major criterium is enough.

iii) Type II diabetic (T2DM) is enough.

iv) Patients from overweight $\left(\mathrm{BMI} \geq 25 \mathrm{~kg} / \mathrm{m}^{2}\right)$ is enough.

- Sum of minor criteria (other comorbidities excluding T2DM and BMI $\geq 25$ $\mathrm{kg} / \mathrm{m}^{2}$ ). Consider age above or equal 65 years old to this analysis.

i) 2 minor clinical/image criteria and 2 minor laboratorial minor criteria.

Or

ii) comorbidities + at least 2 laboratorial minor criteria.

Or

iii) comorbidities + at least 2 clinical/image minor criteria.

Clinical experience hospitalising T2DM, BMI $>$ or equal $25 \mathrm{Kg} / \mathrm{m}^{2}$ even if they are in $\mathrm{T}<\mathrm{D} 6$ is a good option since these patients ruled out, they used to return in respiratory distress with orotracheal criteria. Early hospitalisation for these patients is a choice to perform a short period of hospitalisation, performing MTP pulse "in time", avoiding orotracheal intubation, and an exceedingly long period of hospitalisation.

A QUICK EVALUATION: ANYONE WITH T2DM OR BMI $\geq 25 \mathrm{~kg} / \mathrm{m}^{2}$ OR $\mathrm{LDH}>250 \mathrm{IU} / \mathrm{L}$ OR SatO $2<94 \%$ without $\mathrm{O}_{2}$ supplementation.

\section{CRITERIA TO PERFORM OROTRACHEAL INTUBATION}

In case of refractoriness to the "in time" pulse therapy with Methylprednisolone or in case of late arrival to the emergency room (after D8 of the onset of symptoms or C-Reactive protein greater than or equal to $10 \mathrm{mg} / \mathrm{L}$ ) AND WITH CRITERIA OF OROTRACHEAL INTUBATION as described below.

\section{PERFORM "IN TIME" OROTRACHEAL INTUBATION}

Group A: T2DM, BMI > or equal $25 \mathrm{Kg} / \mathrm{m}^{2}$ (at any age above 18 years.)

-RR > OR IQUAL 25 breath per minute.

OR

--SatO2 < or equal $94 \%$ with $\mathrm{O}_{2}$ supplementation up to $6 \mathrm{~L} / \mathrm{min}$ by nasal catheter.

OR

---Arterial blood gases $\mathrm{PaO}_{2} / \mathrm{FIO}_{2}=200$ - 300

By experience, T2DM and $\mathrm{BMI}>$ or equal $25 \mathrm{Kg} / \mathrm{m}^{2}$ have an outcome 
equal to orotracheal intubation most of the time, and those that perpetuate hypoxemia due to non-intubation have a worse prognosis.

Group B: elderly without comorbidities

-After performance evaluation consider*

--RR > OR IQUAL 30 breath per minute.

OR

---SatO2 < or equal $94 \%$ with $\mathrm{O}_{2}$ supplementation up to $6 \mathrm{~L} / \mathrm{min}$ by nasal catheter.

OR

----Arterial blood gases $\mathrm{PaO}_{2} / \mathrm{FIO}_{2}=200$ - 100

* About the performance criteria in the elderly, it must be evaluated together with the family and know how the elderly were before the infection and not based on the elderly visiting the emergency room, where they are often already incapable due to hypoactive delirium. We cannot determine solely based on what is seen in the emergency room to pulse the patient. The performance evaluation must be careful not to skip skipping with MTP. Someone who could benefit from the pulse and, after the illness, can return to their normal activities.

Group C: person up to 59 years-old without comorbidities

-RR > OR IQUAL 30 breath per minute.

OR

--SatO2 < or equal $93 \%$ with $\mathrm{O}_{2}$ supplementation up to $6 \mathrm{~L} / \mathrm{min}$ by nasal catheter.

OR

---Arterial blood gases $\mathrm{PaO}_{2} / \mathrm{FIO}_{2}=200$ - 100

Group D: glasgow coma scale $<\mathbf{8}$ or in case of airway protection OR if the patient is in cardiac arrest or SatO2 without supplementation < or equal $75 \%$.

Group E: DHL > 300 not reversed after 2 hours of non-invasive ventiltion and $\mathrm{SatO} 2<95 \%$ at rest $=$ they are enough to perform orotracheal intubation.

\section{LDH importance}

The function of the enzyme is to catalyse the reversible conversion of lactate to pyruvate with the reduction of $N A D+$ to $N A D H$ and vice versa.

Conditions that can cause increased LDH in the blood may include liver disease, anaemia, heart attack, bone fractures, muscle trauma, cancers, and infections such as encephalitis, meningitis, encephalitis, and HIV. LDH is also a non-specific marker of tissue turnover, which is a normal metabolic process. Many cancers cause a general increase in LDH levels or an increase in one of its isozymes.

Lactate Dehydrogenase is one of the $H$ transfer (oxidoreductase) enzymes, which catalyses the reversible conversion of pyruvate to lactate using NADH. Basically, the enzyme is involved in the anaerobic metabolism of glucose when oxygen is absent or in limited supply.

Pyruvate + NADH+H+ --- > Lactate + NAD+

When cells become exposed to anaerobic or hypoxic conditions, the produc- 
tion of ATP by oxidative phosphorylation becomes disrupted. This process demands cells to produce energy by alternate metabolism. Consequently, LDH is upregulated in such conditions to cater to the need for energy production. However, lactate produced during the anaerobic conversion of glucose meets a dead end in metabolism. It cannot undergo further metabolism in any tissue except the liver. Hence, lactate is released in the blood and transported to the liver, where $L D H$ performs the reverse reaction of converting lactate to pyruvate through the Cori cycle (In: Farhana A, Lappin SL. Biochemistry, Lactate Dehydrogenase. [Updated 2021 May 7]. In: StatPearls [Internet]. Treasure Island (FL): StatPearls Publishing; 2021 Jan-. Available from: https.// www.ncbi.nlm.nih.gov/ books/NBK557536/).

The $L D$ test can be helpful because it can alert the doctor that cell damage is occurring. An elevated level of $L D$ may be seen with: haemolytic anaemia pernicious anaemia (megaloblastic anaemia), infections such as infectious mononucleosis (mono), meningitis, encephalitis, HIV sepsis, Intestinal, myocardial (heart) and lung (pulmonary) infarction, acute kidney disease, acute liver disease acute muscle injury, pancreatitis bone fractures, testicular cancer, lymphoma or other cancers, severe shock and lack of oxygen (hypoxia). Translating HDL to COVID-19, high LDH values reflect severe hypoxemia with generalized cell damage as proposed by Zanella and Galvão considering NAD/NADH+ deficiency and severe anaerobic cell respiration with a shift to beta-oxidation and consequent inflammation by oxidative stress.

Hospitals that adopt non-invasive ventilation with CPAP, BIPAP, high-flow nasal cannula should not delay intubation if patients meet the aforementioned criteria. The non-rebreathing mask should only be used as a bridge between the moment when intubation is decided and the procedure itself.

MTP pulse should not delay a well-indicated intubation. Pulse and intubate in sequence if there is a criterion for both.

The patient with hypoxemia has greater difficulty in sedation and a worse prognosis due to systemic inflammation.

\section{Methylprednisolone pulse: practical summary}

Perform MTP pulse

- $\quad$ IF T $>$ or equal D6 and T $<$ or equal D8 and CRP $<10 \mathrm{mg} / \mathrm{L}$

AND

- T2DM, BMI $>$ OR equal $25 \mathrm{Kg} / \mathrm{m}^{2}$

AND

- - SatO2 $<95$ without $\mathrm{O}_{2}$ supplementation.

Wait to perform MTP pulse

- -If $\mathrm{O}_{2}>95$ and $\mathrm{T}<\mathrm{D} 6$ : hospitalisation if T2DM or AT least overweight and performe dayly assesment. Performe MTP pulse when SATO2 < 95\% without $\mathrm{O}_{2}$ suplementation.

Perform MTP pulse

In patients with no comorbidities only if: 
- $\quad$ IF T $>$ or equal D6 and $>$ or equal D8 and CRP $<10 \mathrm{mg} / \mathrm{L}$.

AND

- SatO2 $<94 \%$ without $\mathrm{O}_{2}$ supplementation.

Perform MTP pulse in elderly

- $\quad$ IF T $>$ or equal D6 and $>$ or equal D8 and CRP $<10 \mathrm{mg} / \mathrm{L}$.

AND

- SatO2 $<94 \%$ without $\mathrm{O}_{2}$ supplementation.

AND

- Performance evaluation of the elderly that must be carried out by the Geriatrician, when available in the hospital.

C-reactive protein greater than $10 \mathrm{mg} / \mathrm{L}$ does not contraindicate the performance of MTP pulse. However, most medical literature considers that values above $10 \mathrm{mg} / \mathrm{L}$ or $15 \mathrm{mg} / \mathrm{L}$ have the worst results. Thus, we standardized the cytokine storm as CRP values greater than or equal to 10 with at least one associated clinical criterion: RR greater than or equal to 25 or respiratory distress or O2 saturation without supplementation with values less than 94\%. Performing MTP pulse before the storm and at the time of symptom onset between D6-D8 is to perform this procedure at the patient's best time (defervescence phase), even avoiding the march of neutrophils that are responsible for igniting the cytokine storm as well as responsible by autoimmunity events due to the formation of NETs (Neutrophil extracellular traps).

\section{Why are there many criteria if the pulse is secure?}

It is an author opinion: perform MTP pulse is straightforward and, at the same time, complex if clinicians do not have experience. Adverse symptoms like disglycemia, hypertension, psychiatric symptoms may happen, and they need to have a good assessment and management.

MTP pulse is the best management that we have for this moment, but MTP is still far from being the best drug to use. Corticosteroids (CEs) profile covering multiple ways of this inflammation, CEs can block the COVID-19 progression, which does not happen with monotherapy with specific immunobiological drugs. Besides, COVID-19 let us THE LONG COVID-19, a burden with periodic inflammation managed with corticosteroids.

We need more research focusing on drugs that may block the acute disease and THE LONG COVID-19 inflammation but research with no political bias. About bias, I write here a provocation: Hydroxychloroquine, in my opinion, should not be used in acute COVID-19. In Brazil, this drug had an extreme political connotation regardless of whether it works against the disease or not. Nevertheless, let us consider that this drug has been used for years by Rheumatology, bringing quality of life to many people. Now consider THE LONG COVID-19 a chronic inflammatory disease with platelet activation. Hydroxychloroquine is to inhibit platelet activation. Would hydroxychloroquine have any action in this chronic phase of COVID-19?

This medicine has been so demonised that some studies are now abhorred. 
That should not happen, and regardless of which political person released this or that drug, we must focus on whether the drug is, in fact, a medicine that benefits the population or not.

I put here this present fact because I think the same is happening with Methylprednisolone. A helpful drug with falls of prejudice that are blocking its acceptance. I put this fact here because I think the same is happening with methylprednisolone. A useful drug with pounds of prejudice that are blocking its acceptance in the treatment of COVID-19.

ABOUT HOSPITAL DO SERVIDOR ESTADUAL DE SÃO PAULO (HSPE) (HOSPITAL OF STATE SERVANTS)

In 1952, the Department of Medical Assistance to State Civil Servants (Damspe) was approved. The agency would provide medical care to 400,000 people, including 98,000 civil servants and their dependents.

The construction of a hospital that would serve only state employees and their dependents was defined. On January 25, 1957, the government of São Paulo laid the cornerstone for the construction of the State Civil Servant Hospital (HSPE), a building designed to have 15 floors, 200 apartments, 1200 beds and offer care in 15 specialities.

Currently, the HSPE has 721 beds, 949 doctors, 2020 nursing professionals, and highly complex care in 51 medical specialities.

"The Gripário" (INFLUENZA-E.R.) organisation of the HSPE took place on March 18, 2020, the first hospital emergency service aimed at suspected patients or those with the coronavirus in São Paulo. So far, since March 2019, more than 7000 suspected cases have been admitted.

FINAL CONSIDERATIONS (first author)

Every consideration made is based on the practice of almost one and a half year of evaluation of COVID-19 patients, both in the Emergency Room, wards and ICU, in addition to outpatient follow-up after hospital discharge, in addition to an in-depth and practically daily study of the medical literature based in recent publications, always considering the quality of works and publications. There is nothing derived from unique thoughts. There is in this article much contact with the reality of a cruel disease that, in the absence of a specific antiviral drug, it remained for us to deepen the study of the pathophysiology of the virus so that we could better manage COVID patients-19. Finally, I can also explain that the Iranian work is a way to avoid the increase in death caused by COVID-19. I study and understand the possible side effects related to the use of corticosteroids, but we do not have antivirals against SARS-CoV-2 that are satisfactory, not even immunobiological that, alone, inhibit the dramatic effects of chronic COVID-19 or "THE LONG COVID-19". Between dying or using methylprednisolone, we already have a choice based on the Tehran study. The vital issue behind this dilemma is the prejudice against the use of glucocorticoids versus the world need requiring glucocorticoids, a need that outweighs the need to appease the individual ego. The need is real. 